HIAS-E-56

\title{
Parallel Imports and Repair Services
}

\author{
Jota Ishikawa \\ Hitotsubashi University and RIETI \\ Hodaka Morita \\ University of New South Wales \\ Hiroshi Mukunoki \\ Gakushuin University
}

October 2017

Institute for
Advanced Study

Hitotsubashi Institute for Advanced Study, Hitotsubashi University

2-1, Naka, Kunitachi, Tokyo 186-8601, Japan

tel:+81 425808604 http://hias.ad.hit-u.ac.jp/

HIAS discussion papers can be downloaded without charge from:

http://hdl.handle.net/10086/27202

https://ideas.repec.org/s/hit/hiasdp.html

All rights reserved. 


\title{
Parallel imports and repair services*
}

\author{
Jota Ishikawa $^{\dagger}$
}

Hitotsubashi University and RIETI

\author{
Hodaka Morita
}

University of New South Wales

\author{
Hiroshi Mukunoki \\ Gakushuin University
}

October 13, 2017

\begin{abstract}
This study explores the effect of parallel imports on both domestic and foreign countries when the producer may refuse to provide repair and maintenance services for parallel imported units, or charge higher prices for those services. This service discrimination makes it possible for the producer to weaken intra-brand competition and reduce the degree of price convergence between countries. If this is the case, both the positive effect of parallel imports on consumers in the destination country and the negative effect on the producer and consumers in the source country become weaker. If the quality of the good depends on the producer's investment, permitting parallel imports in the presence of the service discrimination could lower the quality, because lower quality leads to a larger price gap between countries. As a result, it is possible that prices increase, consumers lose, and welfare deteriorates in both countries. This negative welfare effect is more likely to emerge as the
\end{abstract}

\footnotetext{
*We wish to thank Yasuhiro Arai, Richard Baldwin, Taiji Furusawa, Tadashi Ito, Tomohiro Kuroda, Keisuke Hattori, Kazunobu Hayakawa, Keisaku Higashida, Toshiyuki Matsuura, Yoichi Sugita, Arijit Mukherjee, Jee-Hyeong Park and participants at the conferences and workshops held at Aalto University, Hitotsubashi University, Kochi University, National Taiwan University, Nova School of Business and Economics, Peking University, and RIETI for their helpful comments and suggestions. Jota Ishikawa acknowledges financial support from the Japan Society for the Promotion of Science through the Grant-in-Aid for Scientific Research (S) Grant Number 26220503, Hodaka Morita acknowledges financial support from the Australian Research Council, and Hiroshi Mukunoki acknowledges financial support from the Japan Society for the Promotion of Science through the Grant-in-Aid for Scientific Research (A) and (C) Grant Numbers 24243034 and 26380310. The usual disclaimer applies.

$\dagger$ Corresponding author: Faculty of Economics, Hitotsubashi University, Kunitachi, Tokyo 186-8601, Japan; Fax: +8142-580-8882; E-mail: jota@econ.hit-u.ac.jp
} 
liberalization of trade in goods proceeds. The prohibition of service discrimination recovers the positive welfare effect.

Key words: parallel imports, service discrimination, goods quality, welfare, trade liberalization

\section{Introduction}

When consumers purchase imported goods, these may be products imported in parallel through distributors not authorized by the original producers, who hold the property rights of those products. These goods are called "parallel imported goods" (PI goods) or "gray market goods." PI goods are not counterfeit goods. They are genuine goods purchased from authorized distributors in the source countries and transported to the destination countries without the consent of the property holders. The unauthorized distributors, or parallel traders, engage in such trade to profit from price differences of the same good between markets in different countries. Specifically, parallel traders earn profits by purchasing the good in a country where the price of the authorized good is low, and reselling it to consumers in a country where the price of the same good is high. The end user of a good might also be a parallel trader if he/she purchases a good in a foreign country and transports it to a different country.

Because there are no multilateral rules regarding the permission of parallel imports (PIs, henceforth), each country can choose whether to permit or prohibit them. ${ }^{1,2}$ PIs are mostly permitted in Japan. In the United States, however, they are only permitted for trademarked goods as long as the US and foreign trademarks are held by the same owner, or different owners are in a parent-subsidiary relationship (Maskus, 2000). The EU members only allow PIs from other EU members. Russia has not liberalized PIs. Although parallel trade is typically observed for pharmaceutical products (e.g., Ganslandt and Maskus, 2004), it also occurs for many other products. NERA (1999) reported that PI goods within the European Union (EU) include footwear and leather goods, musical recordings, motorcars, consumer electronics, domestic appliances, cosmetics and perfumes, clothing, and so on. Yeung and Mok (2013) reported that the market share of parallel imported automobiles in Hong Kong and Singapore was

\footnotetext{
${ }^{1}$ More specifically, countries choose between adopting national exhaustion and international exhaustion of intellectual property rights. Under national exhaustion, property rights expire only in the market where goods are initially sold. Thus, the trademark holders can legally prevent PIs. Under international exhaustion, parallel trade is allowed because property rights expire globally, irrespective of where goods are originally sold by the trademark holders.

${ }^{2} \mathrm{~A}$ few studies have investigated countries' choices of parallel import policies. In a monopoly model, Richardson (2002) showed that all countries permit parallel imports in a global Nash equilibrium if they can choose whether to permit or prohibit parallel imports. Roy and Saggi (2012a) investigated strategic interdependence between countries' PI policies in a North-South model of international oligopoly.
} 
$15 \%-25 \%$, and is $15 \%-17 \%$ in the US and the UK.

PIs encourage international price arbitrages and promote international market integration. From the viewpoint of original producers, parallel trade is usually harmful because it limits their abilities to discriminate prices among countries. ${ }^{3}$ Basically, permitting PIs reduces prices in destination countries and raises prices in the source country. If parallel traders are competitive, the price gaps between countries are reduced to the marginal costs of parallel trade that include tariffs. The price convergence, which is often called the full market integration, benefits consumers in the countries that receive PIs and hurts consumers in the country that originates them.

\subsection{PIs and service discrimination}

Even if PIs are allowed and parallel traders are competitive, this does not always mean that it leads to the full market integration. This is because producers might use instruments to mitigate the negative effect of PIs. One possible way is to reduce the substitutability between the authorized units and the PI units by providing after-sales services, such as repair and maintenance services, only to authorized products. For instance, Nikon Inc. USA, a subsidiary of the Japanese company of optical instruments, Nikon, does not provide support or a warranty service on parallel imported items, including fee-based repair work. ${ }^{4}$ Samsonite, the US luggage manufacturer, employs the same policy in Japan. World Commerce Corp, the Japanese authorized distributor of the Swiss watch company, Franck Muller, refuses to repair parallel imported watches. Firms also discriminate prices in after-sales services and set higher maintenance and repair prices for PI units, while they provide free repairs or charge a lower fee for authorized units. An empirical analysis supports the view that discrimination in after-sales services weakens intra-brand competition between authorized goods and parallel imported goods. Chen, Lai, and

\footnotetext{
${ }^{3}$ Some analyses have suggested that permitting parallel trade may increase the profit of the producer. Anderson and Ginsburgh (1999) suggest that a monopolist might use consumers' arbitrage activities through parallel importation to undertake second-degree price discrimination, if arbitrage costs differ across consumers. Knox and Richardson (2002) show that parallel imports may benefit the producer because they reduce the optimal tariff of the destination country. Raff and Schmitt (2007) found that, in the presence of demand uncertainty, parallel imports lead to larger orders from retailers because they enable retailers to ship unsold inventories to countries where demand turns out to be unexpectedly high. In a duopoly model, Matsushima and Matsumura (2010) found that permitting parallel imports increases profits of all firms because it serves as a commitment device to soften price competition in the destination country. Roy and Saggi (2012b) also showed a similar commitment effect of parallel imports in a different setting. Mukherjee and Zhao (2012) pointed out that parallel imports have the wage reducing effect in unionized markets.

${ }^{4}$ Nikon Inc. USA declares in its website: "Nikon Inc. USA cannot provide any technical support or warranty service on Gray Market items. Additionally Nikon Inc. USA cannot perform any fee-based repair work on Gray Market items. Please do not contact Nikon Inc. USA for help with any Gray Market products."
} 
Yu (2013) investigated Taiwan's Yahoo! auctions of Nikon cameras and showed that authorized goods with a longer duration of warranty and that are repaired by the official dealers have higher transaction prices than PI goods.

Given this background, this study theoretically examines the effect of PIs when a producing firm may refuse to provide repair and maintenance services or may set a higher repair price for a PI good. In this study, refusal of repairs and price discrimination in repair services are together referred to as "discrimination in repair services" or simply "service discrimination." Specifically, we investigate a firm's incentive to discriminate repair services, and how the welfare effect of permitting PIs is associated with such a business practice. In our model, the difference in the demands for the good induces the firm to set different prices in different countries. There are many parallel traders, and the competition among them reduces the price of the PI good by an amount equal to the sum of the price of the authorized good in a low-priced country and a tariff. This implies that, in the absence of service discrimination, the price difference between the two countries reduces to the level of tariffs. We call this price convergence full market integration.

We find that service discrimination works as a tool to weaken the intra-brand competition and makes the domestic and foreign markets only "partially" integrated. Partial market integration means that the firm cannot fully discriminate prices, but can still charge a higher price in a high-demand country than in a low-demand country. By discriminating services, the firm intentionally decreases the attractiveness of the PI good and makes the authorized good and the PI good vertically differentiated. The servicebased product differentiation reduces the degree of price convergence and the firm can partially recover its loss from its inability of discriminating prices between countries. Therefore, the firm always prefers discrimination in terms of repair services for the PI good. It is worth noting that the firm is willing to discriminate services only if it faces PIs. In other words, the firm has no incentive to sell the good that is not subject to repair services in the absence of PIs (see Section ?? for details). We should take into account service discrimination to discuss the economic impacts of parallel trade, because they are inseparably related.

\subsection{Service discrimination and welfare effects of PIs}

With regard to the welfare effects of PIs, they critically depend on whether repair services are discriminated against the PI good, and also on whether the likelihood of the product's breakdown, referred to as the quality in our model, is exogenously given or endogenously determined. The purchased goods may break down for a variety of reasons including inappropriate quality control and inspections in the 
production process, careless handling of the goods during their storage and distribution, and consumers' inadequate ways of using the goods. The producer can reduce the likelihood of breakdown (or increase the quality of the product) by undertaking costly activities such as intensive quality control and inspections, provision of training to workers involved in storage and distribution of the goods, and development of user-friendly manual for consumers. Higher quality product is less likely to break down and lower quality product is more likely to break down. If the repair services are not provided, the consumer's expected utility is increasing in the product quality, whereas, if the repair services are provided, the consumer's utility is not directly affected by the product quality in our model. The quality of the product, however, indirectly affects the consumer's utility because consumers may pay more to bear the cost of repairs.

Let us first summarize the welfare effects of service discrimination given the level of the product quality. Compared to the case of full market integration, the price in a high-demand country becomes higher and consumers in the destination country suffers from service discrimination, given the level of product quality. The service discrimination, however, decreases the prices and benefits consumers in the source country. Thus, given the level of product quality, service discrimination worsens the welfare of the destination country and world welfare, while it benefits consumers and the producer, and improves the welfare of the source country. Nevertheless, permitting PIs with service discrimination realize lower price in a high demand country compared with the price under market segmentation. With the fixed quality of the product, permitting PIs always benefits consumers, improves the welfare in the destination country, and improves world welfare, while it hurts both consumers and producers and also worsens the welfare in the source country.

The producer's endogenous choice of the product quality substantially changes the welfare effects of permitting PIs. Specifically, permitting PIs may worsen consumer surplus and welfare in all countries in the presence of service discrimination, while it has the same directions of welfare changes as those when the quality is fixed in the absence of service discrimination.

Not only PIs affect prices, but also they affect innovation activities. For example, PIs may lead to less cost-reducing $\mathrm{R} \& \mathrm{D}$, or a deterioration of the quality of products and/or the quality of before- and after-sales services. This is because the inability to discriminate prices between markets may reduce the gains from producers' investments in improving the quality of their products and services (Grigoriadis, 2014). Then, an intriguing question is that whether those incentives depend on service discrimination. Among others, we focus on how PIs affect the quality of the product, when the firm engages in costly activities to improve it. 
We show that the effect of parallel imports on the quality depends on whether the firm discriminates repair services. Our findings show that if the firm does not discriminate services and parallel imports realize full market integration, permitting PIs has no effect on the quality of the good that the firm determines. Without service discrimination, the price gap between the two countries is independent of the quality. Besides that, irrespective of whether parallel trade is permitted or not, changes in the quality have the same effect on prices and sales in each market. Then, permitting PIs does not change the effect of an increase in the quality on the firm's profit and the firm chooses the same level of quality in equilibrium.

In contrast, PIs with service discrimination may lower the quality of the good that the firm chooses. This is because a lower quality reduces the substitutability between the authorized good and the PI good, which weakens intra-brand competition or generates a greater profit opportunity in the repair market of the PI good. The lower quality hurts consumers who purchase the PI good in the destination country, because their expected utilities decline. The lower quality also hurts consumers who purchase the authorized good in both countries. This is because a lower quality increases the firm's expected cost for repairs and this cost increase is passed through to the price of the authorized good, at least partly. If this effect is large enough to exceed the price-reducing effect of (partial) market integration in the destination country, permitting parallel imports may increase the prices of the good in all countries, hurt consumers in all countries, and worsen welfare of all countries.

The effect of trade liberalization on the optimal quality also depends on the firm's service discrimination. Trade liberalization basically reduces the firm's cost of exporting and increases the firm's gains from improving the quality and reducing the expected unit cost for repairs. Hence, trade liberalization leads to higher quality if parallel trade is prohibited or parallel trade does not come with service discrimination. With service discrimination, however, trade liberalization may induce the firm to set lower quality. Because trade liberalization reduces the cost of conducting parallel trade, it gives the firm more incentive to differentiate the authorized good and the PI good by setting lower quality. If this additional effect is large enough, the firm has a stronger incentive to lower the quality as the tariff becomes lower. Thus, permitting PIs with service discrimination can hurt consumers and worsen the welfare in the destination country, and this becomes more likely as tariffs fall. These results suggest that, in the presence of service discrimination, the progress of trade liberalization may transform welfare-improving parallel imports into welfare-worsening parallel imports.

These contrasting results provide novel policy implications (see Section 4.3). To evaluate the welfare effects of permitting PIs, it is important to take into account the firm's service discrimination and its 
effects on the firm's choice of the product quality.

\subsection{Relationship to the Literature}

In our model, service discrimination allows the firm to increase its overall profit by vertically differentiating the quality of authorized good and the PI good. The idea that parallel importation allows the manufacturer to vertically price discriminate between the authorized good and the PI good has been previously studied by Ahmadi and Yang (2000). In their model, consumers discount their valuation on the PI goods compared to the authorized goods because of the inconvenience due to market-specific product differentiation or due to service differentiation (e.g., the lack of technical support and warranty). Hence Ahmadi and Yang's (2000) model is not designed to compare cases in which services are discriminated and they are not discriminated, whereas such a comparison is a key element of our analysis. We compare welfare effects of permitting parallel imports under service discrimination and non-discrimination, and show that the comparison result becomes different in an important way when we endogenize the determination of product quality. Furthermore, we show that the effect of trade liberalization on the optimal product quality also depends on whether or not the service is discriminated. In contrast, Ahmadi and Yang (2000) focus on the effect of parallel imports on the firm's profitability and they do not study the welfare effects of parallel imports or the endogenous determination of product quality.

This paper has considered the repair services in the context of international trade. Ishikawa, Morita, and Mukunoki (2016) investigate how the welfare effects of trade liberalization depend on whether and by whom repair services are provided. They show that trade liberalization may hurt the consumers of the importing country and world welfare, if it is not accompanied by FDI in repair services. However, their paper does not consider the effects of parallel imports.

In both Ahmadi and Yang (2000) and Ishikawa, Morita, and Mukunoki (2016), the quality of the good is exogenously given. However, parallel imports and repair services could affect the quality of the good a producer chooses. The distinctive feature of this paper is that it takes into account the firm's choice of the product quality that changes the likelihood of the product's breakdown, and discusses how the discrimination in repair services affects the quality choice and the welfare effects of permitting PIs. The paper also provides a new result with respect to how the effects of PIs are connected to the degree of trade liberalization. We will show that, in the presence of service discrimination, the welfare consequence of permitting PIs is more likely to be negative as trade liberalization proceeds.

There have been some analyses which investigate how permitting PIs affects firms' incentives to 
engage in R\&D activities. Li and Maskus (2006) explore how PIs inhibit the firm's cost-reducing R\&D activities. Valletti (2006) shows that parallel imports reduce the quality of the product when differential pricing is demand based but raise the quality when it is cost based. In a North-South model, Grossman and Lai (2008) show that parallel trade promotes product innovation because it induces the Southern government to change their price control in favor of Northern firms. Matteucci and Reverberi (2014) suggest there is a case where PIs enhance a quality-enhancing R\&D, when the quality affects the consumers' willingness to pay differently between the source and the destination countries. Hwang, Peng, and Shih (2014) suggest whether PIs promote product innovation depends on the market structure of the destination country and the number of the distributors that engage in parallel trade. However, none of these papers has considered how PIs affect the quality of the product when a lower quality means a higher failure rate of the product and the broken units become reusable by repair services.

Quality of the product in our paper has similarity to durability of the product, which has been studied in the industrial organization literature. And several papers in the literature have shown that durable-goods producers may intentionally reduce durability of their products. For instance, Bulow (1986) showed that a durable goods monopolist may reduce the durability of its output to reduce its time inconsistency problem. Waldman $(1996 \mathrm{a}, \mathrm{b})$ claimed that the monopolist has incentive to reduce the durability to reduce the competition between the new units and the old units. More recent papers such as Choi (2001), Fethke and Jaganatthan (2002), Goering and Pippenger (2002), Goering (2007) and Strausz (2009) also considered endogenous determinations of durability. None of them, however, considered the effect of PIs on the firm's choice of durability, let alone how they are related with service discrimination.

The existing studies show that welfare effects of PIs are much more complicated than it seems. Malueg and Schwartz (1994) investigated how uniform pricing induced by parallel importation affects global welfare. They showed that permitting PIs yields lower global welfare if many markets become unserved by the monopolist. Ishikawa (2004) examined a move from segmented to integrated markets in a monopoly model. Generally speaking, permitting PIs promotes price arbitrages and makes markets more integrated. The analysis showed that the welfare effects of the integration crucially depend on the extent of arbitrage and the shape of the marginal cost curve. Maskus and Chen (2004) and MuellerLanger (2012) used a model of vertical control to show that allowing PIs improves global welfare if the cost of undertaking parallel trade is low, but reduces global welfare if the cost is high. In this paper, we show that welfare effect depends on whether the producer discriminates repair services against the PI good, and also whether it optimally chooses the level of the product quality. 
The remainder of the paper is organized as follows. Section 2 develops a monopoly model in which a purchased good may need repair services, and derives the equilibrium without PIs and that under PIs without service discrimination. Section 3 investigates the equilibrium the equilibrium under PIs with service discrimination. Section 4 compares the equilibrium outcomes, discusses the welfare effects of parallel imports, investigates how the endogenous determination of the quality changes them, and provides some policy implications. Section 5 relaxes some assumptions of the basic model and discusses the robustness of the results. Section 6 summarizes the paper and offers concluding remarks. Lastly, the appendix contains the proofs of some propositions in the paper.

\section{Model}

We consider a two-country model with a single firm in the foreign country (country $F$ ) that produces good $x$, which it supplies locally and to the domestic country (country $D$ ). An import tariff, $t$, is imposed on good $x$ by the domestic country. Each consumer purchases at most one unit of good $x$. Consumers in country $i(i=D, F)$ are identical except in their willingness to pay for the good. If consumer $j$ in country $i$ purchases the good at price $p_{i}$, its utility is given by $U_{j i}=v_{j}-p_{i}$, where $v_{j}$ is the consumer $j$ 's willing to pay for the good. We assume each consumer's utility under no purchase is normalized to zero. The population in each country is identical and given by $n$, though the distribution of the willingness to pay is different across the two countries. In this model, only the distribution of $v_{j}$ in each country matters for the equilibrium outcomes. Therefore, we henceforth omit the subscript $j$ from $U_{j i}$ and $v_{j}$ and each consumer's utility is denoted by $U_{i}=v-p_{i}$. In country $D, v$ is uniformly distributed over the interval $[0, b]$ with density $f_{D}=\frac{1}{b}$. In country $F, v$ is uniformly distributed over the interval $[0, k b]$ with density $f_{F}=\frac{1}{k b}$, where $k$ is positive and $k<1$. This means that consumers in country $D$, on average, attach a higher value to good $x$.

If parallel trade is allowed, consumers in each country can purchase the good from either authorized distributors controlled by the firm or other distributors who purchase the good in the other country and resell it through parallel trade without authorization. We call the good purchased from authorized

distributors "the authorized good" and that purchased from parallel importers "the PI good."

After consumers purchase the goods, they may break down because of imperfect quality control. The probability of the good working correctly is $q \in(0,1)$, which is referred to as quality (see Section 1.2 for a discussion) and it is common to both the authorized good and the PI good. Hence, the probability of the good breaking down is $(1-q)$. If the consumers utilize repair services provided by the producing firm, the broken good becomes consumable. However, without repair services, broken goods are useless 
and have zero scrap values. We assume if a consumer purchases the authorized good, the good is subject to free repairs. ${ }^{5}$ However, the firm may refuse to repair the PI good or charge a fee for the repair. The unit cost of production for the firm is given by $c(>0)$, and the unit cost of repairs is given by $m$, which should be lower than $c$.

If parallel trade is allowed, many competitive parallel traders can purchase the good in the country where the price is low and sell it to the country where the price is high. For simplicity, we assume parallel traders incur no additional cost other than the tariff. We only focus on the situation where the firm always provides the good in both countries.

We consider the following three situations: (i) Regime $N$ in which parallel imports are banned in country $D$; (ii) Regime $I$ in which PIs are allowed and the firm provides the same repair services to the consumers purchasing the PI good as those provided to the consumers of the authorized good; and (iii) Regime $R$ in which PIs are allowed and the firm discriminates the repair services against the PI good by either refusing to repair the PI good or charging a fee for the repair. We show that refusing repairs and charging for repairs of the PI good have the same effect on the equilibrium prices and welfare (see Section 5.1 for details). These firms' behaviors are referred to collectively as service discrimination.

The model has four stages. In the first stage, the firm sets authorized prices in country $D$ and country $F$ in all three regimes. In the second stage, consumers in each country purchase the authorized product in all three regimes. If parallel trade is permitted (Regime $I$ and Regime $R$ ), parallel traders may also purchase the authorized product in this stage. In the third stage, nothing happens in Regime $N$. In Regime $I$ and Regime $R$, however, parallel traders export the purchased good to other countries and sell it to consumers who purchase the PI good, if parallel traders earn non-negative profits. There is no time discounting between the second stage and the third stage. Thus, consumers always wait until the third stage if they anticipate that purchasing the PI good will generate higher utility. In the fourth stage, consumers find whether the purchased unit is broken. In Regime $N$ and Regime $I$, any purchased unit is subject to free repairs and consumers always utilize repair services. In Regime $R$, however, only the broken units of the authorized product are subject to free repairs and the broken units of the PI product remain unrepaired if the original producer refuses to repair the PI units. If the purchased units of PI product are subject to fee-based repair services, consumers choose whether they pay for them.

\footnotetext{
${ }^{5}$ We confirm that the firm is willing to offer a full warranty for the authorized good. See Section 5.1.
} 


\subsection{No parallel imports}

As a benchmark, we start with Regime $N$, where PIs are prohibited. In this case, the markets of the two countries are completely segmented (full segmentation). The monopolist is able to make independent decisions in setting the prices in each country. Let $p_{i}$ denote the price the consumer pays. A consumer in country $i$ purchases the good if $U_{i}=v-p_{i} \geq 0$ holds. Under market segmentation, all consumers purchase the authorized good if they buy. Therefore, $p_{i}$ coincides with the price of the authorized good in country $i$. The consumers whose willingness to pay for quality satisfies $v \geq p_{i}$ purchase the good.

The demand for good $x$ in each country is given by

$$
\begin{aligned}
& x_{D}\left(p_{D}\right)=n f_{D}\left(b-p_{D}\right)=n\left(1-\frac{p_{D}}{b}\right), \\
& x_{F}\left(p_{F}\right)=n f_{F}\left(k b-p_{F}\right)=n\left(1-\frac{p_{F}}{k b}\right) .
\end{aligned}
$$

Let $\bar{p}=f_{F} p_{F}+f_{D} p_{D}=\left(p_{F}+k p_{D}\right) / b k$ denote the average price of the good weighted by the densities of the preference distribution. Then, the total consumption of the good becomes

$$
X(\bar{p})=x_{D}\left(p_{D}\right)+x_{F}\left(p_{F}\right)=n(2-\bar{p}) .
$$

The firm's profit is given by

$$
\Pi\left(p_{D}, p_{F}\right)=\left(p_{D}-t\right) x_{D}\left(p_{D}\right)+p_{F} x_{F}\left(p_{F}\right)-\{c+(1-q) m\} X(\bar{p}) .
$$

The first two terms represents the tariff-exclusive revenues from selling in the two countries, and the last term represents the sum of the firm's total cost of production and the expected total cost of repairs. The firm maximizes this profit with respect to $p_{D}$ and $p_{F}$. By solving the first-order conditions, the equilibrium prices are given by

$$
\begin{aligned}
& \widetilde{p}_{D}^{N}=\frac{b+c+t+(1-q) m}{2}, \\
& \widetilde{p}_{F}^{N}=\frac{k b+c+(1-q) m}{2} .
\end{aligned}
$$

Note that these prices are decreasing in $q$, because higher quality means a lower failure rate of the product and thereby decreases the firm's expected cost of repairs, reducing the optimal prices of the authorized good. ${ }^{6}$ To ensure positive sales in each market, $x_{D}\left(\widetilde{p}_{D}^{N}\right)>0$ and $x_{F}\left(\widetilde{p}_{F}^{N}\right)>0$, we assume $b>\max [\{c+(1-q) m\} / k, c+t+(1-q) m]$ holds. The equilibrium average price of the good is given by $\bar{p}^{N}=\left(\widetilde{p}_{F}^{N}+k \widetilde{p}_{D}^{N}\right) / b k$.

\footnotetext{
${ }^{6}$ Section 5.5 discusses what happens if the production cost is positively related to the quality.
} 
By comparing the equilibrium prices, we have $\Delta p^{N} \equiv \widetilde{p}_{D}^{N}-\widetilde{p}_{F}^{N}=\{(1-k) b+t\} / 2>0$. This implies that the firm sets a higher price in the domestic country where consumers' willingness to pay for the good is, on average, higher than in the foreign country. ${ }^{7}$

The equilibrium cut-off level of $v$, above which consumers purchase the good in each country, becomes $\widetilde{v}_{i}^{N}=\widetilde{p}_{i}^{N}$. The equilibrium profits are given by $\Pi^{N}=\Pi\left(\widetilde{p}_{D}^{N}, \widetilde{p}_{F}^{N}\right)$ and the equilibrium consumer surplus in country $F$ and country $D$ are, respectively, given by

$$
\begin{aligned}
C S_{D}^{N} & =\frac{n}{b}\left(b-\widetilde{v}_{D}^{N}\right)\left[\frac{b+\widetilde{v}_{D}^{N}}{2}-\widetilde{p}_{D}^{N}\right]=\frac{n\left(b-\widetilde{p}_{D}^{N}\right)^{2}}{2 b} \\
C S_{F}^{N} & =n_{F} f_{F} \int_{\widetilde{v}_{F}^{N}}^{k b}\left(v-\widetilde{p}_{F}^{N}\right) d v=\frac{n\left(k b-\widetilde{p}_{F}^{N}\right)^{2}}{2 k b} .
\end{aligned}
$$

The equilibrium welfare of each country is given by $W_{D}^{N}=C S_{D}^{N}+t x_{D}\left(\widetilde{p}_{D}^{N}\right)$ and $W_{F}^{N}=C S_{F}^{N}+\Pi^{N}$, and the equilibrium world welfare becomes $W W^{N}=W_{D}^{N}+W_{F}^{N}$.

\subsection{Parallel imports without service discrimination}

If parallel trade is allowed, the price difference of good $x$ between the two countries creates an opportunity for parallel trade. Since there are many competitive parallel traders, the price of the PI good in country $D$ becomes $p_{F}+t$.

The firm is able to choose whether it provides free repair services for the good sold by unauthorized, parallel traders. Suppose it does do so (Regime $I$ ). Then, the good sold directly by the authorized distributors and the good sold by parallel importers are perfect substitutes. This means that if the price of the authorized good, $p_{D}$, is higher than $p_{F}+t$, all consumers purchase the PI good. Each consumer's utility in country $D$ is given by $U_{D}=v-\min \left[p_{D}, p_{F}+t\right]$.

By (5) and (6), if the producer sets the same prices of the authorized goods as those without PIs, then the price gap between the authorized good and the parallel imported good becomes

$$
\widetilde{p}_{D}^{N}-\left(\widetilde{p}_{F}^{N}+t\right)=\Delta p^{N}-t=\frac{(1-k) b-t}{2}
$$

If $(1-k) b \leq t$ holds, we have $\Delta p^{N} \leq t$, implying that the price of the PI good, $\widetilde{p}_{F}^{N}+t$, is higher than the price of the authorized good, $\widetilde{p}_{D}^{N}$. In this case, no consumers in country $D$ purchase the PI good even if the producer charges $\widetilde{p}_{D}^{N}$ and $\widetilde{p}_{F}^{N}$. Then, the producer will set $\widetilde{p}_{D}^{N}$ and $\widetilde{p}_{F}^{N}$ in equilibrium and permitting

\footnotetext{
${ }^{7}$ For simplicity, we only focus on the case with $k<1$ where $\widetilde{p}_{D}^{N}>\widetilde{p}_{F}^{N}$ holds in this paper. Note that if we consider an oligopoly model (see Section 5.4), when $\widetilde{p}_{D}^{N}<\widetilde{p}_{F}^{N}$ holds, the government in the domestic country may implement antidumping policy against the foreign firm.
} 
PIs has no effects on the equilibrium prices and welfare. ${ }^{8}$ To explore the effects of permitting PIs, we put the following assumption throughout the paper.

Assumption $1(1-k) b>t$ holds.

Assumption 1 ensures that $\Delta p^{N}>t$ holds, with which all consumers buy the PI good if the firm sets the same prices as those charged under full market segmentation. We can confirm that the firm has no incentive to set $p_{D}$ lower than $p_{F}+t$ given $\Delta p^{N}>t$ holds. This implies that the firm sets $p_{D} \geq p_{F}+t$ and consumers in country $D$ always pay $p_{F}+t$ if they purchased the good. If the firm sells the authorized good by setting the price $p_{D}=p_{F}+t$ and consumers purchase it, it receives $p_{D}$ but needs to incur the tariff, $t$. If $p_{D}>p_{F}+t$ holds and consumers purchased the PI good, the firm receive $p_{F}$ from selling the good to parallel traders and it doesn't need to incur $t$. In either case, the producer price that the firm receives from serving the good in country $D$ becomes $p_{F}$. In other words, the threat of parallel trade makes the two markets completely integrated and the equilibrium price difference between the two markets is always equal to the tariff level.

Consumers purchase the good if $U_{i} \geq 0$ holds, and the demand in country $F$ is given by (2) and the demand in country $D$ is obtained by substituting $p_{F}+t$ for $p_{D}$ in (1). The firm's profit is obtained by substituting $p_{F}+t$ for $p_{D}$ in (4), which is given by

$$
\Pi\left(p_{D}, p_{F}\right)=\left[p_{F}-\{c+(1-q) m\}\right] X(\bar{p}) .
$$

The weighted average price, $\bar{p}$, is now given by $\bar{p}=\left(k p_{D}+p_{F}\right) / b k=\{(1+t) k+1\} p_{F} /(b k)$.

The firm maximizes (10) with respect to $p_{F}$. Then, the respective equilibrium prices that consumers pay, $\widetilde{p}_{D}^{I}$ and $\widetilde{p}_{F}^{I}$, become:

$$
\begin{aligned}
& \widetilde{p}_{D}^{I}=\widetilde{p}_{F}^{I}+t=\widetilde{p}_{D}^{N}-\frac{k}{(1+k)}\left(\Delta p^{N}-t\right) \\
& \widetilde{p}_{F}^{I}=\widetilde{p}_{F}^{N}+\frac{1}{(1+k)}\left(\Delta p^{N}-t\right) .
\end{aligned}
$$

Note that the equilibrium prices are the weighted average of the equilibrium prices under market segmentation. The equilibrium cut-off level of $v$ in each country becomes $\widetilde{v}_{i}^{I}=\widetilde{p}_{i}^{I}$. We have $\widetilde{p}_{D}^{I}<\widetilde{p}_{D}^{N}$ and $\widetilde{p}_{F}^{I}>\widetilde{p}_{F}^{N}$ implying that PIs without service discrimination increase price in country $F$ and decrease the price in country $D$. The price gap of the authorized good between countries becomes $\Delta p^{I} \equiv \widetilde{p}_{D}^{I}-\widetilde{p}_{F}^{I}=t$. Apparently, $\Delta p^{I}<\Delta p^{N}$ is satisfied and allowing parallel imports decreases the price gap between the countries. The equilibrium average price of the good is given by $\bar{p}^{I}=\left(\widetilde{p}_{F}^{I}+k \widetilde{p}_{D}^{I}\right) / b k$, and $\bar{p}^{I}=\bar{p}^{N}$

\footnotetext{
${ }^{8}$ As we will see in the following analysis, the producer's profit is maximized when it charges the prices under Regime $N$. Therefore, the producer has no incentive to discriminate services if $(1-k) b \leq t$ holds.
} 
holds. Given the uniform distribution of $v$ in each country, the price gap under PIs without service discrimination becomes a mean-preserving contraction of the price gap without PIs. Since the total consumption of the good, which is given by (3), depends only on the average price, permitting PIs without service discrimination has no effect on the total consumption of the good.

Figure 1 depicts the equilibrium prices without PIs and PIs without service discrimination. In the figure, the $d d$ curve and the $f f$ curve represent the demand curve for the good in country $D$ and that in country $F$, respectively.

\section{[Insert Figure 1 around here]}

The equilibrium profit becomes $\Pi^{I}=\Pi\left(\widetilde{p}_{D}^{I}, \widetilde{p}_{F}^{I}\right)$ and the respective equilibrium consumer surplus in each country is given by

$$
\begin{aligned}
& C S_{D}^{I}=n f_{D} \int_{\widetilde{v}_{D}^{I}}^{b}\left(v-\widetilde{p}_{D}^{I}\right) d v=\frac{n\left\{b-\left(\widetilde{p}_{F}^{I}+t\right)\right\}^{2}}{2 b}, \\
& C S_{F}^{I}=n f_{F} \int_{\widetilde{v}_{F}^{I}}^{k b}\left(v-\widetilde{p}_{F}^{I}\right) d v=\frac{n\left(k b-\widetilde{p}_{F}^{I}\right)^{2}}{2 k b} .
\end{aligned}
$$

The equilibrium welfare of each country is given by $W_{D}^{I}=C S_{D}^{I}+t x_{D}\left(\widetilde{p}_{D}^{I}\right)$ and $W_{F}^{I}=C S_{F}^{I}+\Pi^{I}\left(\widetilde{p}_{D}^{I}, \widetilde{p}_{F}^{I}\right)$, and the equilibrium world welfare becomes $W W^{I}=W_{D}^{I}+W_{F}^{I}$.

\subsection{Parallel imports with service discrimination}

We now investigate Regime $R$, where the firm discriminates repair services by either (i) refusing to repair the PI good or (ii) charging a positive fee for the repair. Let $\widetilde{p}_{i}^{R}$ denote the equilibrium price of the authorized good in country $i$ and $\Pi^{R}$ and $C S_{i}^{R}$ are the equilibrium profit of the firm and the equilibrium consumer surplus in country $i$, respectively. We can show that both (i) and (ii) qualitatively yields the same equilibrium outcomes and welfare. The detailed analysis is provided in Section 5.1. Here, we choose the case with the refusal of repairs to derive the equilibrium under service discrimination.

Suppose the firm refuses to repair the PI good (Regime $I$ ). The equilibrium prices, profit, and consumer surplus are respectively given by $\widetilde{p}_{i}^{I}$, $\Pi^{I}$, and $C S_{i}^{I}$. However, if $q<1$, the authorized good and the PI good generate different expected utilities, even if they are sold at the same price. Specifically, if a consumer in country $D$ buys an authorized good at price $p_{D}$, his/her utility becomes

$$
U_{D}^{A}=v-p_{D}
$$

Suppose that consumers are risk neutral. If the consumer buys a PI good at price $p_{F}+t$, then his/her expected utility becomes

$$
U_{D}^{P I}=q v-\left(p_{F}+t\right) .
$$


Let $v_{D}^{A}$ be the preference parameter of the consumer who is indifferent between buying an authorized good and a PI good $\left(U_{D}^{A}=U_{D}^{P I}\right)$, and $v_{D}^{P I}$ be the parameter for the consumer who is indifferent between buying a PI good and no purchase $\left(U_{D}^{U}=0\right)$. We have

$$
\begin{aligned}
v_{D}^{A} & =\frac{p_{D}-\left(p_{F}+t\right)}{1-q} \\
v_{D}^{P I} & =\frac{p_{F}+t}{q}
\end{aligned}
$$

By comparing $v_{D}^{A}$ and $v_{D}^{P I}$, we have

$$
v_{D}^{A}-v_{D}^{P I}=\frac{q p_{D}-\left(p_{F}+t\right)}{(1-q) q}
$$

This means that if $p_{D}>\left(p_{F}+t\right) / q$ holds, which means that the "quality-adjusted price" of the PI good is lower than the price of the authorized good, consumers with preference parameter $v \in\left[v_{D}^{A}, b\right]$ buy the authorized good and consumers with parameter $v \in\left[v_{D}^{P I}, v_{D}^{A}\right]$ buy the PI good. Even if the price of the PI good is lower than that of the authorized good, the consumers with high $v$ buy the authorized good because the price difference is insufficient for them to compensate for the risk of the good being broken down and not being repaired. The consumers with low $v$ buy the PI good because they value the good less and are more sensitive to the price of the good.

If $v_{D}^{A}>v_{D}^{P I}$ holds, both the authorized good and the PI good are purchased in equilibrium. If $v_{D}^{A} \leq v_{D}^{P I}$ holds, all consumers purchase the authorized good. The equilibrium ranking between $v_{D}^{A}$ and $v_{D}^{P I}$ and the firm's optimal pricing depend on the quality of the product, $q$.

There exist threshold values $q_{H}$ and $q_{L}, 0<q_{L}<q_{H} \leq 1 .^{9}$ The equilibrium pattern of consumption depends on the level of $q$ : (i) high quality $\left(q \in\left(q_{H}, 1\right)\right)$, (ii) middle quality $\left(q \in\left(q_{L}, q_{H}\right)\right)$, and (iii) low quality $\left(q \in\left[0, q_{L}\right)\right)$. This implies that the functional forms of consumer surplus and the firm's profit may take different forms. Specifically, in all three cases, the equilibrium consumer surplus in country $F$ is given by

$$
C S_{F}^{R}=\frac{n\left(b k-\widetilde{p}_{F}^{R}\right)^{2}}{2 k b} .
$$

However, the equilibrium profit and the equilibrium consumer surplus take the different forms depending on the level of $q$. In the following, we elaborate the equilibrium prices, the equilibrium profit, and the equilibrium consumer surplus in the three cases.

\footnotetext{
${ }^{9}$ Note that $q_{H}$ is strictly smaller than 1 if $b$ and $m$ are large and $c$ and $t$ are small. See the proof of Lemma 2.
} 


\subsubsection{High quality}

Suppose $q \in\left(q_{H}, 1\right)$ holds, then the demand for the authorized good and the demand for the PI good in country $D$ are, respectively, given by

$$
\begin{aligned}
x_{D}^{A}\left(p_{D}, p_{F}\right) & =n f_{D}\left[b-v_{D}^{A}\right]=n\left[1-\frac{p_{D}-\left(p_{F}+t\right)}{(1-q) b}\right], \\
x_{D}^{P I}\left(p_{D}, p_{F}\right) & =n f_{D}\left[v_{D}^{A}-v_{D}^{P I}\right]=n\left[\frac{q p_{D}-\left(p_{F}+t\right)}{(1-q) q b}\right],
\end{aligned}
$$

while the demand in country $F$ is given by (2). An increase in $p_{F}$ not only raises the price of the good in country $F$, but also the price of the PI good in country $D$. These price changes increase the demand for the authorized good and decrease the demand for the PI good. An increase in $p_{D}$, on the other hand, has the opposite effects. The sum of the consumption of the authorized good and that of the PI good in country $D$ becomes

$$
x_{D}^{A}\left(p_{D}, p_{F}\right)+x_{D}^{P I}\left(p_{D}, p_{F}\right)=n\left[1-\frac{\left(p_{F}+t\right)}{b q}\right] .
$$

It depends on the quality-adjusted price of the PI good. The total consumption of the good is given by

$$
X^{+}\left(\bar{p}, p_{F}\right)=x_{F}\left(p_{F}\right)+x_{D}^{A}\left(p_{D}, p_{F}\right)+x_{D}^{P I}\left(p_{D}, p_{F}\right)=X(\bar{p})-\frac{n(1-q)\left(p_{F}+t\right)}{b q} .
$$

We have confirmed in Section 2.1 that, without service discrimination, the total consumption is independent of $q$. Here, the total consumption depends on $q$. Given the prices, an increase in the quality increases the total consumption because it decreases the effective price of the PI good. The firm's profit is given by

$$
\begin{aligned}
\Pi^{+}\left(p_{D}, p_{F}\right)= & p_{D} x_{D}^{A}\left(p_{D}, p_{F}\right)+p_{F} x_{F}\left(p_{F}\right)+p_{F} x_{D}^{P I}\left(p_{D}, p_{F}\right) \\
& -(1-q) m\left\{x_{F}\left(p_{F}\right)+x_{D}^{A}\left(p_{D}, p_{F}\right)\right\}-c X^{+}\left(\bar{p}, p_{F}\right) .
\end{aligned}
$$

The third term of this equation is the revenue earned from selling the good to the parallel traders. By solving $\partial \Pi^{+}\left(p_{D}, p_{F}\right) / \partial p_{F}=0$ and $\partial \Pi^{+}\left(p_{D}, p_{F}\right) / \partial p_{D}=0$, the equilibrium prices of this case become:

$$
\begin{aligned}
& \widetilde{p}_{D}^{R}=\widetilde{p}_{F}^{R}+t+\frac{(1-q)(b+m)}{2} \equiv \widehat{p}_{D}, \\
& \widetilde{p}_{F}^{R}=\widetilde{p}_{F}^{N}+\frac{k[b(q-k)-\{t+(1-q) m\}]}{2(q+k)} \equiv \widehat{p}_{F} .
\end{aligned}
$$

The price gap of authorized good between the countries becomes $\Delta p^{R} \equiv \widetilde{p}_{D}^{R}-\widetilde{p}_{F}^{R}$. It is apparent that $\Delta p^{R}>t$ holds and the price difference between the two markets does not reduce to the level of the tariff. In other words, the two markets are not fully integrated, but only partially integrated. The extra price difference over the tariff level is due to the "quality premium" of the authorized good, because 
the authorized good is subject to free repair services and its expected quality is higher than that of the PI good. Here, the quality premium is given by $\widetilde{p}_{D}^{R}-\left(\widetilde{p}_{F}^{R}+t\right)=\Delta p^{R}-t=(1-q)(b+m) / 2>0$. As $q$ decreases, consumers in country $D$ regard the authorized good and the PI good as becoming more vertically differentiated, and the firm is able to discriminate more on pricing. The equilibrium average price of the authorized good, $\bar{p}^{R}=\left(\widetilde{p}_{F}^{R}+k \widetilde{p}_{D}^{R}\right) / b k$, satisfies $\bar{p}^{R}>\bar{p}^{N}=\bar{p}^{I}$ and permitting PIs with service discrimination reduces the total consumption of the good. ${ }^{10}$ By (3) and (24),

Figure 2 depicts the equilibrium prices in this case. Here, the $d d$ curve represent the overall demand curve for the authorized good and the PI good, which is given by (23). The quality-adjusted price of the PI good, $\left(\widetilde{p}_{F}^{R}+t\right) / q$, determines the total sales. Then, the a curve in the figure represents the demand for the authorized good, which is given by (21). Given the price of the authorized good, $\widetilde{p}_{D}^{R}$, the sales of the authorized good is determined on the $a a$ curve. The total sales minus the sales of the authorized good corresponds to the sales of the PI good.

\section{[Insert Figure 2 around here]}

The equilibrium profit of this case is given by $\Pi^{R}=\Pi^{\prime}\left(\widetilde{p}_{D}^{R}, \widetilde{p}_{F}^{R}\right)$, and the equilibrium consumer surplus in each country is given by

$$
\begin{aligned}
C S_{D}^{R} & =n f_{D}\left[\int_{\widetilde{v}_{D}^{A}}^{b}\left(v-\widetilde{p}_{D}^{R}\right) d v+\int_{\widetilde{v}_{D}^{P I}}^{\widetilde{v}_{D}^{A}}\left\{q v-\left(\widetilde{p}_{F}^{R}+t\right)\right\} d v\right] \\
& =\frac{n\left(b-\widetilde{p}_{D}^{R}\right)^{2}}{2 b}+\frac{n\left\{q \widetilde{p}_{D}^{R}-\left(\widetilde{p}_{F}^{R}+t\right)\right\}^{2}}{2 b q(1-q)} .
\end{aligned}
$$

The first term of (28) represents the surplus that would have been obtained if all consumers purchased the authorized good given $\widetilde{p}_{D}^{R}$. In equilibrium, some consumers purchase the PI good at $\widetilde{p}_{F}^{R}+t$. Consumers of the PI good include those who would have purchased the authorized good if the PI good is unavailable. They also include new consumers who did not purchase the authorized good at $\widetilde{p}_{D}^{R}$. These demand shifts and new purchases generates the consumers' gains from purchasing the PI good. ${ }^{11}$ The second term of (28) represents this additional consumer surplus.

\subsubsection{Middle quality}

Suppose $q \in\left(q_{L}, q_{H}\right]$ holds. In this case, the firm opts to block PIs by setting $p_{D}=\left(p_{F}+t\right) / q$, rather than accommodating them. In this case, the firm maximizes $(4)$ subject to $p_{D}=\left(p_{F}+t\right) / q$. The

\footnotetext{
${ }^{10}$ We can calculate that $\bar{p}^{R}-\bar{p}^{N}=(1-q)\left(\widetilde{p}_{F}^{R}-\widetilde{p}_{F}^{N}\right)>0$. By (3) and $(24), X^{\prime}\left(\bar{p}^{R}, \widetilde{p}_{F}^{R}\right)-X\left(\bar{p}^{N}\right)=-\left\{X\left(\bar{p}^{N}\right)-\right.$ $\left.X\left(\bar{p}^{R}\right)\right\}-n(1-q)\left(\widetilde{p}_{F}^{R}+t\right) /(b q)<0$.

${ }^{11}$ More specifically, if the PI good is unavailable, consumers of the PI good with $v \in\left[\widetilde{p}_{D}^{R}, \widetilde{v}_{D}^{A}\right)$ would have purchased the authorized good while those with $v \in\left[\widetilde{v}_{D}^{P I}, \widetilde{p}_{D}^{R}\right)$ would not have purchased the authorized good.
} 
optimal prices become:

$$
\begin{aligned}
& \widetilde{p}_{D}^{R}=\frac{k \widetilde{p}_{D}^{N}+q\left(\widetilde{p}_{F}^{N}+t\right)}{k+q^{2}} \equiv \grave{p}_{D} \\
& \widetilde{p}_{F}^{R}=\frac{k\left(q \widetilde{p}_{D}^{N}-t\right)+q^{2} \widetilde{p}_{F}^{N}}{k+q^{2}} \equiv \grave{p}_{F} .
\end{aligned}
$$

Because $\widetilde{p}_{D}^{R}=\left(\widetilde{p}_{F}^{R}+t\right) / q>\widetilde{p}_{F}^{R}+t$ holds, we have $\Delta p^{R}>t$. The firm is able to make the price differential between the two countries more than the tariff level. The quality premium of the price difference is

$$
\widetilde{p}_{D}^{R}-\left(\widetilde{p}_{F}^{R}+t\right)=\Delta p^{R}-t=\frac{(1-q)}{q}\left(\widetilde{p}_{F}^{R}+t\right)>0 .
$$

The equilibrium average price of the good is given by $\bar{p}^{R}=\left(\widetilde{p}_{F}^{R}+k \widetilde{p}_{D}^{R}\right) / b k$, and $\bar{p}^{R}>\bar{p}^{N}=\bar{p}^{I}$ holds. ${ }^{12}$ Since the total consumption of the good is given by (3) in this range of $q$, PIs with service discrimination decreases the total consumption of the good.

Figure 3 depicts the equilibrium prices in this case. Since $\widetilde{p}_{D}^{R}=\left(\widetilde{p}_{F}^{R}+t\right) / q$ holds, consumers purchase only the authorized good in equilibrium.

\section{[Insert Figure 3 around here]}

The equilibrium profit is given by $\Pi^{R}=\Pi\left(\widetilde{p}_{D}^{R}, \widetilde{p}_{F}^{R}\right)$ and the equilibrium consumer surplus in country $D$ becomes $C S_{D}^{R}=n\left(b-\widetilde{p}_{D}^{R}\right)^{2} / 2 b$.

\subsubsection{Low quality}

Finally, suppose $q \in\left(0, q_{L}\right]$ holds, all consumers in country $D$ prefer the authorized good, if they buy one. In this case, $\widetilde{p}_{D}^{N}<\left(\widetilde{p}_{F}^{N}+t\right) / q$ holds. This implies that the firm is able to block PIs, even if it completely discriminates the prices between the two countries. Therefore, the firm charges $\widetilde{p}_{F}^{R}=\widetilde{p}_{F}^{N}$ and $\widetilde{p}_{D}^{R}=\widetilde{p}_{D}^{N}$ in equilibrium. Here, the firm's refusal to repair by itself blocks PIs, making the two markets completely segmented. The equilibrium price gap satisfies $\Delta p^{R}=\Delta p^{N}$.

The equilibrium profit and the equilibrium consumer surplus in country $D$ are respectively given by $\Pi^{R}=\Pi^{N}$ and $C S_{D}^{R}=C S_{D}^{N}$.

In summary, the equilibrium price in country $i, \widetilde{p}_{i}^{R}$, becomes $\widetilde{p}_{i}^{R}=\widehat{p}_{i}$ if $q_{H} \neq 1$ and $q \in\left(q_{H}, 1\right)$, $\widetilde{p}_{i}^{R}=\grave{p}_{i}$ if $q \in\left(q_{L}, q_{H}\right]$, and $\widetilde{p}_{i}^{R}=\widetilde{p}_{i}^{N}$ if $q \in\left(0, q_{L}\right]$. In all three cases, the equilibrium welfare of each country is given by $W_{D}^{R}=C S_{D}^{R}+t\left\{x_{D}^{A}\left(\widetilde{p}_{D}^{R}, \widetilde{p}_{F}^{R}\right)+x_{D}^{P I}\left(\widetilde{p}_{D}^{R}, \widetilde{p}_{F}^{R}\right)\right\}$ and $W_{F}^{R}=C S_{F}^{R}+\Pi^{R}$, where $x_{D}^{P I}\left(\widetilde{p}_{D}^{R}, \widetilde{p}_{F}^{R}\right)=0$ for $q \leq q_{H}$. The equilibrium world welfare becomes $W W^{R}=W_{D}^{R}+W_{F}^{R}$.

\footnotetext{
${ }^{12}$ We have $\bar{p}^{R}-\bar{p}^{N}=k(1-q)\left\{q \widetilde{p}_{D}^{N}-\left(\widetilde{p}_{F}^{N}+t\right)\right\} /\left(k+q^{2}\right)>0$.
} 


\section{Price effects of permitting parallel imports}

In Section 2, we have derived the equilibrium prices under three regimes $(N, I$, an $R)$. Here, we compare the equilibrium prices given the level of the quality to explore the price effects of parallel imports.

If there is no service discrimination, permitting PIs changes the regime from Regime $N$ to Regime I. We have the following lemma.

Lemma 1 Given the level of $q, \widetilde{p}_{F}^{N}<\widetilde{p}_{F}^{I}<\widetilde{p}_{D}^{I}<\widetilde{p}_{D}^{N}$ and $\widetilde{p}_{F}^{I}+t=\widetilde{p}_{D}^{I}$ hold.

Without service discrimination, parallel imports make the two markets completely integrated, and the producer price of selling the good is given by $p_{F}=p_{D}-t$, no matter where the firm sells the good. Then, the profit-maximizing prices becomes the weighted average of the equilibrium prices under market segmentation. As a result, the firm increases the price in the foreign country and decreases the price in the domestic country such that $\Delta p^{I}=\widetilde{p}_{D}^{I}-\widetilde{p}_{F}^{I}=t$ is realized. As is shown in section $2.2, \widetilde{p}_{D}^{I}<\widetilde{p}_{D}^{N}$ and $\widetilde{p}_{F}^{I}>\widetilde{p}_{F}^{N}$ hold and the consumers in foreign country are indifferent between purchasing the authorized good and the PI good.

Service discrimination makes the quality of the authorized good higher than that of the PI good when the firm refuses to repair the PI good. As a result, the firm is able to sustain the price difference between the two countries above the tariff level. We have the following lemma.

Lemma 2 Under regime $R$, there exist threshold values $q_{H}$ and $q_{L}, 0<q_{L}<q_{H} \leq 1$ with the following properties.

(i) Suppose $q \in\left(q_{H}, 1\right)$. Then $\left(\widetilde{p}_{F}^{R}+t\right) / q<\widetilde{p}_{D}^{R}<\widetilde{p}_{D}^{N}$ hold. In the equilibrium, some consumers purchase the PI good whereas some other consumers purchase the authorized good in country D.

(ii) Suppose $q \in\left(q_{L}, q_{H}\right]$. Then $\left(\widetilde{p}_{F}^{R}+t\right) / q=\widetilde{p}_{D}^{R}<\widetilde{p}_{D}^{N}$ hold. In the equilibrium, all consumers purchase the authorized good and no consumers purchase the PI good in country F.

(iii) Suppose $q \in\left(0, q_{L}\right]$. Then $\widetilde{p}_{D}^{R}=\widetilde{p}_{D}^{N} \leq\left(\widetilde{p}_{F}^{R}+t\right) / q$ hold. In the equilibrium, all consumers purchase the authorized good and no consumers purchase the PI good in country F.

Lemma 2 suggests that, depending on the level of $q$, we have three cases regarding the firm's pricing. The logic behind Lemma 2 can be explained as follows. Recall the equilibrium under Regime $N$ in which consumers in country $i(i=D, F)$ with $v \geq \widetilde{v}_{i}^{N}=\widetilde{p}_{i}^{N}$ purchase the authorized good at the price of $\widetilde{p}_{i}^{N}$. Now let us turn to Regime $R$ that we consider here, and suppose for the moment that the monopolist sets $p_{i}=\widetilde{p}_{i}^{N}$, the same prices as in the equilibrium of Regime $N$. In country $D$, consumers have an option of purchasing the PI good at the price of $\widetilde{p}_{F}^{N}+t$ and leave it unrepaired should the good break 
down. Consider the consumer with the cut-off $v=\widetilde{v}_{D}^{N}$. The consumer purchases the authorized good rather than the PI good if and only if $\widetilde{v}_{D}^{N}-\widetilde{p}_{D}^{N} \geq q \widetilde{v}_{D}^{N}-\left(\widetilde{p}_{F}^{N}+t\right) \Leftrightarrow \widetilde{p}_{D}^{N} \leq \widetilde{p}_{F}^{N}+t+(1-q) \widetilde{v}_{D}^{N}$. We find that this condition holds when $q$ is small enough satisfying $q \in\left[0, q_{L}\right]$. That is, when the probability of the good breaking down $(1-q)$ is relatively high, the attractiveness of the PI good without repair is too low to impose a binding constraint on the monopolist's profitability. The result is that the monopolist can make the same profit as in Regime $N$ by charging the same prices as in Regime $N$ in both countries.

Let us turn to the case of $q>q_{L}$. The PI good without repair services is now sufficiently attractive so that, if the monopolist continues to choose $p_{i}=\widetilde{p}_{i}^{N}(i=D, F)$, some consumers in country $D$ with relatively small $v$ (but still $v \geq \widetilde{v}_{D}^{N}$ ) purchase the PI good rather than the authorized good. That is, the attractiveness of the PI good is now sufficiently high so that it imposes a binding constraint on the monopolist's profitability. When $q$ is in an intermediate range (satisfying $q \in\left(q_{L}, q_{H}\right]$ ), the attractiveness of the PI good is moderate in the sense that, in equilibrium, the monopolist chooses $p_{D}$ and $p_{F}$ such that all consumers who purchase the good in country $D$ purchase the authorized good at $p_{D}$ and no consumers purchase the PI good. However, when $q$ is higher than $q_{H}$, the attractiveness of the PI good becomes substantially high so that the monopolist's profit-maximizing choice is to induce some consumers with intermediate value of $v$ to purchase the PI good, selling the authorized good to high- $v$ consumers only.

By combining Lemmas 1 and 2, we can compare the equilibrium prices under the three regimes. Because the service discrimination reduces the degree of market integration, $\widetilde{p}_{D}^{I}<\widetilde{p}_{D}^{R}$ and $\widetilde{p}_{F}^{R}<\widetilde{p}_{F}^{I}$ always hold.

Proposition 1 Compare equilibrium prices under the three regimes. We have (i) - (iii).

(i) Suppose $q \in\left(q_{H}, 1\right)$. Then $\widetilde{p}_{D}^{I}<\left(\widetilde{p}_{F}^{R}+t\right) / q<\widetilde{p}_{D}^{R}<\widetilde{p}_{D}^{N}$ and $\widetilde{p}_{F}^{N}<\widetilde{p}_{F}^{R}<\widetilde{p}_{F}^{I}$ hold.

(ii) Suppose $q \in\left(q_{L}, q_{H}\right]$. Then $\widetilde{p}_{D}^{I}<\left(\widetilde{p}_{F}^{R}+t\right) / q=\widetilde{p}_{D}^{R}<\widetilde{p}_{D}^{N}$ and $\widetilde{p}_{F}^{N}<\widetilde{p}_{F}^{R}<\widetilde{p}_{F}^{I}$ hold.

(iii) Suppose $q \in\left(0, q_{L}\right]$. Then $\widetilde{p}_{D}^{I}<\widetilde{p}_{D}^{R}=\widetilde{p}_{D}^{N} \leq\left(\widetilde{p}_{F}^{R}+t\right) / q$ and $\widetilde{p}_{F}^{N}=\widetilde{p}_{F}^{R}<\widetilde{p}_{F}^{I}$ hold.

Thus, PIs with service discrimination lead to the same direction of price changes as PIs without service discrimination do if $q>q_{L}$ holds, but has no effect if $q \leq q_{L}$ holds. Service discrimination, however, reduces the extent of the price changes. This implies that, given PIs are permitted, prohibiting service discrimination decreases the price in the destination country and increases the price in the source country. 


\section{Welfare effects of permitting parallel imports}

In Section 3, we have investigated how parallel imports change the consumer prices in each country. These price changes affect consumers in each country, the firm, and the welfare of each country. Here, we compare welfare under the three regimes to explore the welfare effects of permitting PIs and how the firm's service discrimination changes the effects. This section also discusses policy implications of the results.

In the following analysis, we first discuss the welfare effects of PIs in the baseline model, where the level of the quality of the product, $q$, is exogenously given. Then, we extend the analysis to the situation in which $q$ is endogenously determined by the firm, and re-examine the welfare effects of permitting PIs. As we will see below, endogenous choice of quality complicates the welfare effects of permitting PIs in the presence of service discrimination, while it does not qualitatively change the welfare effects in the absence of service discrimination.

\subsection{Exogenous quality}

Let us start with the case with exogenous quality of the product. Without service discrimination, permitting PIs change the regime from Regime $N$ to Regime $I$. In Regime $I$, the firm must sell the authorized good with the constraint that the consumer prices satisfy $p_{F}=p_{D}+t$. PIs fully integrate the two markets and the firm's per-unit profit is always given by $\widetilde{p}_{F}^{I}-c=\widetilde{p}_{D}^{I}-(c+t)$ no matter where it sells the good. ${ }^{13}$ We have $\Pi^{I}<\Pi^{N}$ because the inability to discriminate prices due to PIs hurt the domestic firm. PIs affect consumers in each country differently. Because the authorized good and the PI good are homogeneous in Regime $I$, the price decrease from $\widetilde{p}_{D}^{N}$ to $\widetilde{p}_{D}^{I}$ benefits consumers in country $D$ and the price increase from $\widetilde{p}_{F}^{N}$ to $\widetilde{p}_{F}^{I}$ hurts consumers in country $F$. Therefore, $C S_{D}^{N}<C S_{D}^{I}$ and $C S_{F}^{I}<C S_{F}^{N}$ hold. Because the price decrease increases the imports of country $D$, permitting PIs increases the tariff revenue of country $D$, given the tariff level. Since both consumer surplus and the tariff revenue increase, we have $W_{D}^{N}<W_{D}^{I}$. In contrast, $W_{F}^{I}<W_{F}^{N}$ holds because consumer surplus and the firm's profit decreases in country $F$.

Let us next investigate how service discrimination changes the welfare effect of permitting PIs. With service discrimination, in order to block consumers from purchasing the PI good in country $D$, the firm

\footnotetext{
${ }^{13}$ If the firm supplies the good in country $F$ through its own distributors, it receives $\widetilde{p}_{F}^{I}$ but $t$ is incurred by the firm. Hence, its per-unit profit is $\widetilde{p}_{F}^{I}-(c+t)$. If the firm supplies the good in country $F$ through (competitive) parallel traders, it receive $\widetilde{p}_{D}^{I}$ but $t$ is incurred by parallel traders. In this case, its per-unit profit becomes $\widetilde{p}_{D}^{I}-c$. Since $\widetilde{p}_{F}^{I}-\widetilde{p}_{D}^{I}=t$ holds, we have $\widetilde{p}_{D}^{I}-c=\widetilde{p}_{F}^{I}-(c+t)$.
} 
must set the prices such that they satisfy $p_{D} \leq\left(p_{F}+t\right) / q$. If the quality of the product is low enough to satisfy $q \in\left(0, q_{L}\right]$, even if the firm charges the same prices as those without PIs, $\widetilde{p}_{D}^{N}$ and $\widetilde{p}_{F}^{N}$, these prices satisfy $\widetilde{p}_{D}^{N} \leq\left(\widetilde{p}_{F}^{N}+t\right) / q$ and the firm does not need to adjust prices to block the PI good. In this case, permitting PIs has no effect and the same equilibrium outcomes as those in Regime $N$ are realized in Regime $R$ : $\Pi^{R}=\Pi^{N}, C S_{D}^{R}=C S_{D}^{N}, C S_{F}^{R}=C S_{F}^{N}, W_{D}^{R}=W_{D}^{N}$, and $W_{F}^{R}=W_{F}^{N}$.

For $q \in\left(q_{L}, 1\right)$, however, the quality difference between the authorized good and the PI good is not so large and all consumers will buy the PI good if the firm continues to change $\widetilde{p}_{D}^{N}$ and $\widetilde{p}_{F}^{N}$. Then, the price constraint is binding and the firm sets the prices such that $p_{D}=\left(p_{F}+t\right) / q$ holds to block the PI good, if $q$ is not so high such that $q \in\left(q_{L}, q_{H}\right]$ holds. If $q$ is high such that $q \in\left(q_{H}, 1\right)$ holds, the firm earns higher profit by setting $p_{D}>\left(p_{F}+t\right) / q$ and letting some consumers purchase the PI good in country $D$ than the profit with blocking the PI good. Note that the firm always has an option to block the PI good by manipulating the level of prices to satisfy $\widetilde{p}_{D}^{R}=\left(\widetilde{p}_{F}^{R}+t\right) / q$. This means that if the firm sets the prices such that some consumers purchase the PI good (or some consumers of the PI good are refrain from paying the repair price), the firm earns a higher profit than if it blocks the PI. More specifically, the firm accommodates parallel trade because it can earn an additional profit from selling the good to parallel traders and the (overall) price in each country becomes closer to the price under market segmentation. However, if $q$ is small, the prices that accommodate PIs substantially reduce the profits from selling the authorized good. Thus, the firm chooses to block them.

In either case, the constraint is less strict than the constraint under Regime $I$ as long as $q<1$. Therefore, the firm's profit, consumer surplus in each country, and the welfare of each country lie between their respective level under Regime $N$ and the level under Regime $I .{ }^{14}$ We have the following proposition.

Proposition 2 Compare equilibrium profit of the firm, consumer surplus and welfare of each country under the three regimes. We have (i) and (ii).

(i) Suppose $q \in\left(q_{L}, 1\right)$. Then $\Pi^{I}<\Pi^{R}<\Pi^{N}, C S_{D}^{N}<C S_{D}^{R}<C S_{D}^{I}, C S_{F}^{I}<C S_{F}^{R}<C S_{F}^{N}$, $W_{D}^{N}<$ $W_{D}^{R}<W_{D}^{I}$ and $W_{F}^{I}<W_{F}^{R}<W_{F}^{N}$ hold.

\footnotetext{
${ }^{14}$ With $q \in\left(q_{H}, 1\right)$, PIs create a new market in country $D$ for consumers with lower willingness to pay. Nevertheless, PIs always lower the profit because they decrease the profits from selling the authorized good in both countries, and this negative effect always dominates the positive profits from selling the PI good to new consumers in country $D$. Although the consumers of the PI good faces a lower price with service discrimination $\left(\widetilde{p}_{F}^{R}+t \leq \widetilde{p}_{F}^{I}+t\right),\left(\widetilde{p}_{F}^{R}+t\right) / q-\widetilde{p}_{D}^{I}=$ $\left(\widetilde{p}_{F}^{R}+t\right) / q-\left(\widetilde{p}_{F}^{I}+t\right)>0$ holds, implying that the quality adjusted price of the PI good becomes higher and the total imports becomes lower with service discrimination. Therefore, $C S_{D}^{R}<C S_{D}^{I}$ and $W_{D}^{R}<W_{D}^{I}$ hold, even if some consumers purchase the PI good in this range of $q$.
} 
(ii) Suppose $q \in\left(0, q_{L}\right]$. Then $\Pi^{I}<\Pi^{R}=\Pi^{N}, C S_{D}^{N}=C S_{D}^{R}<C S_{D}^{I}, C S_{F}^{I}<C S_{F}^{R}=C S_{F}^{N}$, $W_{D}^{N}=W_{D}^{R}<W_{D}^{I}$ and $W_{F}^{I}<W_{F}^{R}=W_{F}^{N}$ hold.

We can also compare the world welfare. Because parallel imports reduces the firm's monopoly power to set the prices and reduces the efficiency loss caused by the price discrimination, permitting PIs always improves world welfare, given the level of $q$.

Proposition 3 Compare equilibrium world welfare under the three regimes. We have (i) and (ii).

(i) Suppose $q \in\left(q_{L}, 1\right)$. Then $W W^{N}<W W^{R}<W W^{I}$ holds.

(ii) Suppose $q \in\left(0, q_{L}\right]$. Then $W W^{N}=W W^{R}<W W^{I}$ holds.

It has been a controversial issue whether governments should apply antitrust laws to service discrimination against parallel imported goods. Given that PIs are permitted and given the level of $q$, Proposition 2 suggests that there is a strong conflict of interest between the source country (country $F$ ) and the destination country (country $D$ ) in allowing service discrimination. The source country supports service discrimination while the destination country opposes it. From the standpoint of world welfare, PIs should be permitted irrespective of whether services are discriminated. However, prohibiting service discrimination realizes higher world welfare.

\subsection{Endogenous quality}

Up to this point, we have discussed the welfare effects of PIs and service discrimination when $q$ is exogenously given. As explained in the Introduction, one concern over allowing PIs is that the reduced profits of firms owing to market integration will decrease the gains from firms' innovation activities and will lead to a deterioration of product quality. Here, we investigate how PIs affect the firm's incentive to provide better product quality that increases the "quality" of the good in the sense that consumers worry less about breaking down. We will show that the firm is able to use service discrimination more effectively as a tool to discriminate prices, if it can choose the level of the quality.

To this end, we add a new stage before the first-stage (i.e., stage zero) in which the firm chooses the quality of the product. Existing studies that have examined the quality effect of PIs have not explicitly considered the possibility that the good breaks down. We examine endogenous determinations of the quality, when higher quality means less probability of the good being broken down.

We suppose the firm must incur the fixed cost, $K(q)$, to produce the good with the quality, $q$. The fixed cost reflects the costs of making $R \& D$ activities to develop a product with a lower failure rate, the costs of introducing instruments that provide a more precise quality inspection, the costs of seeking 
suppliers that provide more durable parts and components in the manufacturing process, and so on. It is natural to suppose that this fixed cost increases as the quality of the product increases. Hence, it is assumed that $K(0)=0, K^{\prime}(q)>0$ and $K^{\prime \prime}(q) \geq 0$. Specifically, we assume that the fixed cost is quadratic in $q$ and given by $K(q)=\beta q^{2} / 2$, where $\beta$ is positive and constant. Let $\widetilde{q}^{N}, \widetilde{q}^{I}$, and $\widetilde{q}^{R}$ respectively represent the profit-maximizing levels of $q$ under Regime $N, R$, and $I$.

\subsubsection{Welfare worsening parallel imports with service discrimination}

Let us now investigate how the firm's endogenous choice of the quality changes the welfare effects of permitting PIs. Recall that, when the level of $q$ is exogenously given, we have that $C S_{D}^{N} \leq C S_{D}^{R}<C S_{D}^{I}$, $C S_{F}^{I}<C S_{F}^{R} \leq C S_{F}^{N}, \Pi^{I}<\Pi^{R} \leq \Pi^{N}, W_{D}^{N} \leq W_{D}^{R}<W_{D}^{I}, W_{F}^{I}<W_{F}^{R} \leq W_{F}^{N}$, and $W W^{N} \leq W W^{R}<$ $W W^{I}$ hold, with equality if and only if $q \in\left(0, q_{L}\right]$ (see Propositions 2 and 3). Although service discrimination diminishes the impact of PIs, PIs with service discrimination neither reduce consumer surplus and the welfare in the importing country nor worsen world welfare, compared with the case where PIs are prohibited. When the firm endogenously determines the quality of the product and it discriminates services, permitting parallel imports can hurt consumers and the welfare in the importing country, and also can worsen world welfare.

Let us start with the welfare effects of permitting PIs without service discrimination. Under both Regime $N$ and Regime $I$, the presence of the repair cost means the increased probability of breaking down raises the firm's expected cost of undertaking the repairs, $(1-q) m$. We call this effect the costincreasing effect of the lower quality. Since consumers always utilize repair services for free without PIs or PIs without service discrimination, the decrease in $q$ does not affect the eventual quality of the good and thereby has no effect on the price gaps between the countries, $\Delta p^{N}$ and $\Delta p^{I}$. Therefore, only the cost-increasing effect matters and $\Pi^{N}$ and $\Pi^{I}$ (which do not include the fixed cost, $K(q)$, to realize quality $q$ ) are always increasing in $q$, implying that a decline in the quality always reduces the firm's profitability, if PIs are banned or the firm cannot discriminate the repair services. Because consumers' willingness to pay for the good is uniformly distributed in each country, the reduction in the international price gap from Regime $N$ to Regime $I$ does not affect the total consumption of the good (see Section 2.2). The increase in the cost of undertaking repairs also raises the equilibrium prices of the good, but the magnitudes of the price changes is the same between Regime $N$ and Regime $I$. Therefore, the magnitudes of the cost-increasing effect also become the same and we have $\widetilde{q}^{N}=\widetilde{q}^{I}$ since $\partial \Pi^{I} / \partial q=\partial \Pi^{N} / \partial q>0$ always hold. ${ }^{15}$ Since PIs without service discrimination do not change the level

\footnotetext{
${ }^{15}$ We have $\partial \Pi^{N} / \partial q=\partial \Pi^{I} / \partial q=N[(1+k)[b k-\{c+(1-q) m\}]+\{(1-k) b-t\} k] m /(2 b k)>0$, because $b>\{c+(1-q) m\} / k$
} 
of the product quality, the directions of the changes in consumer surplus and welfare are the same as those with exogenous $q .{ }^{16}$

Proposition 4 Even when $q$ is endogenously determined, $C S_{D}^{N}<C S_{D}^{I}, C S_{F}^{I}<C S_{F}^{N}, W_{D}^{N}<W_{D}^{I}$, $W_{F}^{I}<W_{F}^{N}$ and $W W^{N}<W W^{I}$ always hold.

Note that both the price gap without PIs, $\Delta p^{N}$, and the price gap without service discrimination, $\Delta p^{I}$, are independent of $q .{ }^{17}$ With service discrimination, a decrease in $q$ not only increases the expected cost of undertaking the repairs but also decreases the quality of the PI good and thereby widens the equilibrium price gap, $\Delta p^{R}$ for $q \in\left(q_{L}, 1\right) .{ }^{18}$ Therefore, a decrease in $q$ increases the firm's ability to discriminate prices in the presence of service discrimination. The effect is called the marketsegmentation effect of a decline in quality. Because of the market-segmentation effect, an increase in $q$ not only increases $K(q)$ but also makes the price constraint stricter and reduces the price gap.

Since PIs with service discrimination decrease the total consumption of the good for $q \in\left(q_{L}, 1\right)$ (see Sections 2.3.1 and 2.3.2), they definitely reduce the sales of the good that are subject to repair services. Hence, PIs with service discrimination reduce the cost-increasing effect of a decrease in $q$ on the firm's profitability, making the firm less willing to improve the quality of the good. ${ }^{19}$

Because of the presence of the market-segmentation effect and the lesser cost-increasing effect, PIs with service discrimination can lower the equilibrium level of the quality. Specifically, if the marginal cost for improving quality (i.e. $\left.K^{\prime}(q)\right)$ is small enough such that $\widetilde{q}^{N}=\widetilde{q}^{I}>q_{L}$ holds, $\widetilde{q}^{R}<\widetilde{q}^{N}=\widetilde{q}^{I}$ can and $(1-k) b>t$ hold.

${ }^{16}$ As Schwarts (1990) and Malueg and Schwarts (1994) have suggested, PIs without service discrimination (i.e., Regime I) improve world welfare compared to the case with the monopolistic third-price discrimination (i.e., Regime $N$ ), as long as all markets are served and PIs weakly increase the total consumption of the good. If we consider a non-uniform distribution of $v$ and PIs strictly increase the total sales, the cost-increasing effect is larger under Regime $I$ and we will have $\widetilde{q}^{N}<\widetilde{q}^{I}$. However, the higher quality enhances the positive welfare effect of PIs without service discrimination and it does not qualitatively affect the results of Proposition 4.

${ }^{17}$ In Regime $N, \Delta p^{N}$ is independent of $q$ because an increase in $q$ reduces $\widetilde{p}_{D}^{N}$ and $\widetilde{p}_{F}^{N}$ by the same degree. In Regime $I, \Delta p^{I}=t$ always holds.

${ }^{18}$ For $q \in\left(q_{L}, 1\right)$, the firm needs to satisfy $p_{D}=\left(p_{F}+t\right) / q$ to block the PI good. Even if $q$ becomes sufficiently high such that the firm let some consumers to buy the PI good by setting $p_{D}>\left(p_{F}+t\right) / q$, the analysis in Section 2.3 .1 suggests that an increase in $q$ decreases the price difference of the authorized good between the countries, $\Delta p^{R}$.

${ }^{19}$ If we consider the non-uniform distribution of $v$ and the price convergence by permitting PIs has an effect to increase the total consumption of the good, the total consumption of the good under Regime $R$ may be larger than that under Regime $N$. In this case, the larger cost-increasing effect gives the firm more incentive to increase $q$ under Regime $R$. Even so, $\widetilde{q}^{R}<\widetilde{q}^{N}$ can hold because of the market segmentation effect and $\widetilde{q}^{R}<\widetilde{q}^{I}$ always holds. Therefore, the main results of the paper remain unchanged. See also footnote 16 . 
hold. ${ }^{20}$ Alternatively, if $K^{\prime}(q)$ is large enough such that $\widetilde{q}^{N}=\widetilde{q}^{I} \leq q_{L}$ holds, then we have $\widetilde{q}^{R}=\widetilde{q}^{N}=\widetilde{q}^{I}$ and permitting PIs has no effect on the optimal quality, irrespective of service discrimination.

Figure 4 depicts an example of the determination of the optimal level of the quality in each regime. In this example, the optimal level of $q$ satisfy $\widetilde{q}^{R}<\widetilde{q}^{N}=\widetilde{q}^{I} \cdot{ }^{21}$

\section{[Insert Figure 4 around here]}

As mentioned above, a lower quality increases the cost of repairs. The increased cost is passed through to the prices of the good. Given that $\widetilde{q}^{R}<\widetilde{q}^{N}$ holds, this cost-increasing effect of a decline in $q$ increases both $p_{D}$ and $p_{F}$, hurting consumers in both countries and causing an efficiency loss. Because $p_{F}$ increases, the effect also increases the quality-adjusted price of the PI good (i.e., $\left.\left(p_{F}+t\right) / q\right)$. As Proposition 2 suggests, a decline in the quality raises the price in the importing country within Regime $R$. Therefore, if the price-increase due to a decline in $q$ dominates the direct effect of price arbitrages that decreases $p_{D}$, permitting PIs with service discrimination hurts consumers and worsens the welfare in the importing country. Since permitting parallel imports with service discrimination still hurts consumers and the welfare of exporting country, it worsens world welfare in this situation.

Proposition 5 When $q$ is endogenously determined, there is a set of parameterization where $C S_{D}^{R}<$ $C S_{D}^{N}, W_{D}^{R}<W_{D}^{N}$, and $W W^{R}<W W^{N}$ hold.

When the product quality is endogenously determined, there is a case where PIs with service discrimination decrease consumer surplus, the welfare in the importing country, and worsens world welfare, while PIs without service discrimination increase them by Proposition 4.

Thus, the producer's service discrimination may transform welfare-improving PIs into welfare-worsening ones. In the short run, where the firm does not change the quality of the product, PIs conventionally improves consumer surplus and the welfare in the initially high-priced, destination country. It also improves world welfare. In the long run, where the firm optimally chooses the quality of the product,

\footnotetext{
${ }^{20}$ Parallel imports with service discrimination do not necessarily reduce $q$. If $K^{\prime}(q)$ is small enough such that $\widetilde{q}^{R} \in\left(q_{H}, 1\right)$ holds, the market for the authorized good and the market for the PI good coexist in country $D$. Under Regime $R$ with $q \in\left(q_{H}, 1\right)$, a decline in $q$ affects the firm's profit from selling the good to parallel traders since it changes the relative demand for the PI good. We call this effect the PI-market effect. The PI-market effect is either positive or negative because the demand for the PI good is an inverted-U shaped in $q$, which complicates the ranking between $\widetilde{q}^{R}$ and $\widetilde{q}^{N}=\widetilde{q}^{I}$. If $\widetilde{q}^{R} \in\left(q_{L}, q_{H}\right]$ holds, the PI-market effect is absent and $\widetilde{q}^{R}<\widetilde{q}^{N}$ always holds.

${ }^{21}$ The parameters other than $q$ are set as follows: $n=100, b=40, k=1 / 3, c=5, m=1, t=3$, and $\beta=100$. In this case, the cut-off levels of $q$ become $q_{H}=0.68758$ and $q_{L}=0.51191$. In the numerical example, we have $\widetilde{q}^{N}=\widetilde{q}^{I}=$ $0.69737>\widetilde{q}^{R}=0.51538$.
} 
allowing PIs to promote price arbitrages is backfiring for the destination country. In other words, blocking PIs may benefit the destination country, because consumers can buy the good with a better quality in the absence of parallel imports. In this case, prohibiting service discrimination not only decreases the price in the destination country given the level of quality (see Proposition 1) but also increases the quality of the good, improving the welfare of the destination country and world welfare. To recover the welfare-improving nature of PIs, service discrimination should be prohibited.

\subsubsection{Trade liberalization and welfare-worsening parallel imports}

We have shown that PIs can be welfare-worsening for all countries when $q$ is endogenously determined, but the likelihood of the case depends on parameter values. Here, we focus on the tariff level, $t$, and how the reduction of $t$ changes the welfare effects of allowing PIs.

When the firm optimally chooses $q, t$ affects the equilibrium level of $q$. On the one hand, trade liberalization enhances the firm's incentive to increase $q$ by increasing the profit from exporting and, thereby, the marginal gains from increasing the quality. ${ }^{22}$ Thus, without service discrimination or without PIs, the former effect always dominates the latter, and trade liberalization leads to a higher level of $\widetilde{q}^{N}$ and $\widetilde{q}^{I}$.

However, in Regime $R$, trade liberalization may reduce $\widetilde{q}^{R}$. Even if trade liberalization increases $\widetilde{q}^{R}$, the extent of the increase in $\widetilde{q}^{R}$ may be less than those of $\widetilde{q}^{N}$ and $\widetilde{q}^{I}$. Recall that, in Regime $R$, a decline in $q$ may increase the firm's profitability due to the market-segmentation effect. Then, since lower $t$ increases the attractiveness of the PI good, it may also increase the firm's incentive to choose lower $q$ to offset partly the damage from the increased arbitrage pressure. Because of this extra incentive, trade liberalization may decrease $\widetilde{q}^{R}$ or widen the gap between $\widetilde{q}^{R}$ and $\widetilde{q}^{N}$ even if it increases $\widetilde{q}^{R} .^{23}$ Figure 5 depicts a case where trade liberalization decreases $\widetilde{q}^{R} \cdot{ }^{24}$

\section{[Insert Figure 5 around here]}

As the gap between $\widetilde{q}^{R}$ and $\widetilde{q}^{N}$ increases, permitting PIs is more likely to decrease the consumer surplus and welfare in country $D$ and worsens world welfare in the presence of service discrimination. This in turn suggests that trade liberalization may make PIs with service discrimination more likely to be welfare-worsening. We have the following proposition.

\footnotetext{
${ }^{22}$ We have $\partial^{2} \Pi^{N} /(\partial t \partial q)=\partial^{2} \Pi^{I} /(\partial t \partial q)=-N m / 2 b<0$.

${ }^{23}$ When $\widetilde{q}^{R} \in\left(q_{L}, q_{H}\right]$ holds, the PI-market effect is absent and only the market-segmentation effect works under service discrimination. In this case, $\widetilde{q}^{R}<\widetilde{q}^{N}=\widetilde{q}^{I}$ always holds, and we can show that trade liberalization always widens the gap between $\widetilde{q}^{R}$ and $\widetilde{q}^{N}=\widetilde{q}^{I}$.

${ }^{24}$ See the proof of Proposition 6.
} 
Proposition 6 Consider a tariff reduction from $t_{0}$ to $t_{1}\left(<t_{0}\right)$. When $q$ is endogenously determined, there is a set of parameterization where $C S_{D}^{N}<C S_{D}^{R}, W_{D}^{N}<W_{D}^{R}$, and $W W^{N}<W W^{R}$ hold at $t=t_{0}$, but $C S_{D}^{R}<C S_{D}^{N}, W_{D}^{R}<W_{D}^{N}$, and $W W^{R}<W W^{N}$ hold at $t=t_{1}$.

When $q$ is fixed, $C S_{D}^{R}>C S_{D}^{N}$ and $W_{D}^{R}>W_{D}^{N}$ always hold (see Proposition 2). However, when $q$ is endogenously determined, the choice of lower $q$ induced by PIs may result in lower consumer surplus and lower welfare in country $D$. It may also worsen world welfare. And, if lower $t$ increases the firm's incentive to reduce $q$ or diminishes its incentive to increase $q$, trade liberalization makes PIs more likely to be welfare-worsening.

\subsection{Policy implication}

We have seen that the welfare effects of PIs depend on whether repair services are discriminated against the PI good and whether the quality of the product is fixed or endogenously determined. The results of the paper provide some useful policy implications.

$>$ From the viewpoint of the importing country (country $D$ ), prohibiting the discrimination in repair services benefits the domestic consumers and improves the domestic welfare. As is shown in Section 1.1, however, the service discrimination are prevalent in the real world. Even if governments recognize service discrimination, they may not require the original producer to support PI goods. ${ }^{25}$ The governments of the importing countries should introduce a more rigid regulation to prevent the service discrimination if they permit PIs.

Even if the importing country has a regulation to ban the discrimination in repair services, the original producers may not be able to provide the repair services for PI goods due to technical reasons. For instance, they may lack physical and human resources to provide the services for PI goods. Japan Fair Trade commission basically bans producers' refusals to repair PI goods if the producers intentionally discriminate against the PI goods, but the commission takes the position that the refusals do not automatically violate the antitrust laws if the producers face difficulties in providing the repair services. ${ }^{26}$ Under the situation, the consumers in the importing country cannot avoid the discrimination in repair services and permitting PIs always changes the regime from Regime $N$ to Regime $R$. If the quality of the

\footnotetext{
${ }^{25}$ For instance, although Australian Competition and Competition Commission cautions that consumers of PI goods "may not get assistance such as product/technical support or repair/spare part facilities from the local manufacturer or their representative," it says that "the local manufacturer is not required to help you if the product develops a fault." See https://www.accc.gov.au/consumers/sales-delivery/buying-parallel-imports (accessed on March 5, 2017).

${ }^{26}$ See http://www.jftc.go.jp/dk/soudanjirei/ryutsutorihiki/sonota/seigen1.html (accessed on March 5, 2017, written in Japanese).
} 
product is fixed, the government of the importing country should still permit PIs because Propositions 2 and 3 suggest that PIs still decrease the consumer price and increase the amount of imports, which in turn increase consumer surplus and the welfare of the importing country, and also improve world welfare. If the quality is endogenously determined, however, Proposition 5 suggests that PIs with service discrimination could increase the consumer price, decrease the amount of imports in the importing countries, worsen consumer surplus, the domestic welfare, and world welfare. In the latter case, the importing country should rather prohibit PIs.

With regard to the relationship between parallel-import policy and trade policy of the importing country, Proposition 6 tells us that, in the presence of discrimination in repair services, a reduction of import tariff may turn welfare-improving PIs into welfare-worsening ones. Recently, many developing countries newly joined the WTO and have committed to lower tariffs, and the proliferation of free trade agreements enhance trade liberalization all over the world. The result implies that, unless service discrimination are prohibited, attempts to integrate markets by permitting PIs may fail in a world with low tariffs. Prohibiting service discrimination becomes more important as trade liberalization proceeds.

Besides that, when a tariff reduction decreases the optimal level of quality in the presence of service discrimination, service discrimination can increase the optimal tariff of the importing country that is set to maximizes its welfare. This is because a higher tariff leads to higher quality. In contrast, a tariff reduction always increases the optimal quality in the absence of service discrimination, which decreases the optimal tariff. This implies that service discrimination can decrease the importing country's incentive to lower tariffs and undermine the progress of trade liberalization in goods.

\section{Discussion}

In this section, we explore the robustness of these results by relaxing some assumptions made in the basic model.

\subsection{Price discrimination in repair services}

Here, we consider an alternative situation where the monopolist may provide repair services for the PI good, but a repair price is charged against the PI good. Let $r$ denote the repair price the firm charges for the PI good in country $D$. We find that the equilibrium in this case is economically equivalent to the equilibrium in the case where the firm refuses to repair the PI good. To see the logic, suppose that the firm chooses $p_{F}$ to sell the authorized good in country $F$, and that, in country $D$, the firm wishes to 
sell the good without repair services to consumers with $v \in\left[v^{+}, v^{++}\right)$and the good with repair services to consumers with $v \in\left[v^{++}, b\right]$, where $v^{+}=\left(p_{F}+t\right) / q<v^{++}<b$. In the case of repair refusal, the firm can achieve this outcome by choosing $p_{D}=p_{F}+t+(1-q) v^{++}$so that $v-p_{D} \geq q v-\left(p_{F}+t\right)$ holds if and only if $v \in\left[v^{++}, b\right]$. Whereas, in the case of price discrimination in repair services, the firm can achieve the same outcome by choosing $p_{D} \geq p_{F}+t+(1-q) r$ and $r=v^{++}$. If $p_{D}>p_{F}+t+(1-q) r$, consumers with $v \in\left[v^{++}, b\right]$ purchase the PI good and repair services, whereas, if $p_{D}=p_{F}+t+(1-q) r$, they are indifferent between purchasing the PI good and repair services, and the authorized good. In any case, the firm's overall profit is identical between the case of refusal to repair and the case of price discrimination in repair services. This in turn implies that, for $q \in\left(q_{H}, 1\right)$, the equilibrium outcome is economically equivalent between the two cases; besides the analogous logic applies to establish the equivalence between the two cases for all $q<q_{H}$ as well. We have the following proposition.

Proposition 7 In equilibrium, the overall price of the PI good under the fee-based repair service is the same as the price of the authorized good under the refusal of repairs.

Therefore, the refusal of repairs and the fee-based repair services for the PI good are qualitatively indifferent for the firm and consumers, and their effect on the quality of the product discussed in the next session is also indifferent. In other words, the equilibrium in the case of the fee-based repairs of the PI good practically coincides with the equilibrium under the refusal of repairs.

The equilibrium pricing of the firm is summarized as follows (see the proof of Proposition 7 for details): the firm sets (i) the prices such that some consumers of the PI good are unwilling to repair the broken units for $q \in\left(q_{H}, 1\right)$; (ii) the prices such that all consumers of the authorized good and the PI good repair the broken units for $q \in\left(q_{L}, q_{H}\right)$; and (iii) the same overall prices as those without PIs and all consumers repair the broken units for $q \in\left[0, q_{L}\right)$.

\subsection{Fee-based repairs for the authorized good}

We have assumed that the firm offers a full warranty to the buyers of the authorized good. Here, we show that this assumption does not affect the qualitative results of our basic model and the firm actually prefers the full warranty in some cases. Suppose parallel importation is prohibited and let $s_{i}$ denote the repair price that the firm sets for repairing the authorized unit in country $i$. Consumers repair the broken units of the authorized good if $v_{i} \geq s_{i}$ holds. That is, the utility gain from the repair exceeds the repair price. Consumers primarily purchase the authorized good if $q v_{i} \geq p_{i}$. These inequalities suggest that there exist consumers who buy the authorized good, but never purchase the repair services if and only if $s_{i}>p_{i} / q$ holds. Without loss of generality, we set $t=0$ for expositional convenience. 
Given that $s_{i}>p_{i} / q$ holds, the profit of the firm in country $i$ is given by

$$
\pi_{i}\left(p_{i}, s_{i}\right)=\left[p_{i}+(1-q) s_{i}-\{c+(1-q) m\}\right] x_{i}^{s}\left(p_{i}\right)+n f_{i}\left(p_{i}-c\right)\left(\frac{q s_{i}-p_{i}}{q}\right),
$$

where $x_{F}^{s}\left(p_{F}\right)=n f_{F}\left(k b-s_{F}\right)$ and $x_{D}^{s}\left(p_{D}\right)=n f_{D}\left(b-s_{D}\right)$. By maximizing $\pi_{i}\left(p_{i}, s_{i}\right)$ with respect to $p_{i}$ and $s_{i}$, the optimal prices become $p_{F}^{s}=(c+b k q) / 2, p_{D}^{s}=(c+b q) / 2, \widehat{s}_{F}=(b k+m) / 2$, and $\widehat{s}_{D}=(b+m) / 2$. However, these prices fail to satisfy the supposition that $s_{i}>p_{i} / q$ holds.

Therefore, the firm sets the repair prices such that every consumer of the authorized good prefers to pay for the repair services. In this case, consumers whose willingness to pay satisfies $v_{i} \geq p_{i}+(1-q) s_{i}$ buy the good and all of them purchase the repair services. Let $P_{i}=p_{i}+(1-q) s_{i}$ denote the overall price of the authorized good. Then, the firm's overall profit becomes

$$
\Pi^{s}\left(P_{D}, P_{F}\right)=\sum_{i=D, F} \pi_{i}\left(P_{i}\right)=\left[P_{i}-\{c+(1-q) m\}\right] x_{i}\left(P_{i}\right)
$$

where $x_{i}(\cdot)$ is defined in (1) and (2). Because (33) has the same functional form as (4), the profitmaximizing level of each price also coincides $\left(\widetilde{P}_{i}=\widetilde{p}_{i}\right)$, as does the equilibrium profit: $\Pi^{s}\left(\widetilde{P}_{D}, \widetilde{P}_{F}\right)=$ $\Pi\left(\widetilde{p}_{D}^{N}, \widetilde{p}_{F}^{N}\right)$.

Because the firm's profit is larger when all consumers utilize the repair services, the combination of the good's price and the repair prices does not matter to the firm, as long as the overall price is equal to $\widetilde{p}_{i}$ and they are consistent with $s_{i} \leq p_{i} / q$. If the firm set a higher repair price, the good's price becomes lower. If the firm provides a full warranty, it means that the firm sets a higher price to cover the cost of the repairs.

In the presence of PIs, the firm becomes more willing to provide the full warranty in country $F$ to keep the price of the authorized good high and to mitigate the arbitrage pressure. If the firm does not provide a full warranty in country $D$, the authorized good and the PI good becomes perfectly substitutable and the firm captures the quality premium of the authorized good by setting a high repair price. After all, the overall price of the authorized good in country $D$ becomes the same as the price of the authorized good with the full warranty.

\subsection{Repair services by ISOs}

Until now, we have restricted our attention to the case where only the original firm can provide the repair services. Here, we consider the case in which independent service organizations (ISOs) are also able to provide the repair services for the PI good. We assume there are many ISOs and the competition among them reduces the repair prices to their marginal cost. 
The original firm of the good should have more technical information about the good than the ISOs, and will stock more parts and components that are necessary to repair the good. Hence, it is natural to assume that the quality of the repair services performed by the firm is not lower than the quality performed by the ISOs. Let $\mu \in(0,1]$ represents how well a repair recovers the original quality of good $x$. As $\mu$ approaches one, the quality gap between the unbroken unit and the repaired unit narrows, and the quality is fully recovered when $\mu=1$. The level of $\mu$ reflects the extent to which the repair services performed by ISOs recover the "physical" quality of the good.

Let $\mu w$ denote the unit cost of undertaking repair services when performed by ISOs. The unit cost of repairs is increasing in $\mu$ because it should be more costly for the firm to return the quality to the original quality. The ISOs may also incur a higher unit cost of repairs, but their less effective repair services may come with a lower cost. Therefore, we leave $w$ to be either higher or lower than $m$.

First, suppose $\mu=1$. In other words, ISOs provide the same quality of repair services as the original firm. In this case, even if the firm refuses to repair the PI good, consumers can repair the PI good by paying $w$ to an ISO. The overall price of the PI good becomes $p_{F}+t+(1-q) w$. Then, the firm needs to set $p_{D} \leq p_{F}+t+(1-q) w$ to sell the authorized good. If $(1-q) w$ is larger than $\widetilde{p}_{D}^{N}-\left(\widetilde{p}_{F}^{N}+t\right)$ given by (9), the firm can set the same prices as those under market segmentation. Otherwise, the equilibrium international price difference becomes $t+(1-q) w$, and becomes larger as $q$ becomes smaller. Note that, unless $w=0$, the entry of competitive ISOs realizes a higher profit for the firm than the profit that is realized if the firm cannot discriminate repair services.

Second, suppose $\mu<1$. To make clear the analysis, we set $w=0$ so that ISOs provides virtually free repairs. However, the free repairs cannot realize full market integration because the authorized unit and the PI unit repaired by ISOs are imperfect substitutes. If the firm refuses to provide the repair services for the PI good, it can attract consumers to buy the authorized good by setting $p_{D}$ and $p_{F}$, such that

$$
p_{D}=\frac{p_{F}+t}{\mu}
$$

holds. Because $\mu<1$, we have $p_{D}-\left(p_{F}+t\right)=(1-\mu)\left(p_{F}+t\right) / \mu>0$. If this price difference is larger than $\widetilde{p}_{D}^{N}-\left(\widetilde{p}_{F}^{N}+t\right)$, the full market segmentation is realized by the service discrimination.

If $\mu<1$ and $w>0$ : the equilibrium price difference reflects the above two effects. Accordingly, if the ISOs' quality of repair services is lower than the firm's quality or the ISOs incur a positive cost of repair services, the presence of competitive ISOs does not realize full market integration. The original firm's service discrimination becomes less effective, but it is still effective, and a decrease in $q$ may expand the international price difference and increase the firm's profit. 


\subsection{Oligopoly}

We have assumed that only a single firm can produce the good. Here, we discuss how the existence of a rival firm affects the firm's incentives to discriminate services and to choose the level of the quality.

Suppose that there is a firm in country $D$ (firm $D$ ) that compete with the firm in country $F$ (firm $F$ ), which produce a product that is imperfectly substitutable with the good produced by firm $F$. We assume firm $D$ does not export its product to country $F$, because of the high fixed cost of exporting. With firm $D$, the market competition in country $D$ reduces the equilibrium price of the authorized good $F$ in country $D$. Therefore, the price gap between the countries becomes smaller than the baseline model. Besides that, service discrimination becomes a less effective tool to discriminate prices, because firm $F$ must take into account its price settings that an increase in the price of the authorized good shifts the demand from good $F$ to good $D$ in country $D$. We call the effect the demand-shift effect of service discrimination. Because of the demand-shift effect, firm $F$ becomes less willing to reduce the quality of good $F$ to increase the quality gap between the authorized unit and the PI unit of good $F$. This is because a lower quality increases the price of the authorized good, shifting the demands from good $F$ to good $D$ in country $D$. Although the presence of the domestic firm changes the extent of the price gap and that of profit gains from both service discrimination and reducing $q$, the qualitative results of our model would remain unchanged.

Alternatively, suppose that there is another firm in country $F$ (firm $F^{\prime}$ ), which produces a differentiated product and sell it in both countries $D$ and $F$. In this case, PIs exert downward pressure on the prices of both goods in country $D$. As in the case with firm $D$, the presence of the rival firm reduces each firm's gains from discriminating services and decreasing $q$. A difference is that the levels of each good's quality are determined by a Nash equilibrium of the two firms' strategic choices of the quality. Even though the choices of the quality becomes much more complicated under oligopoly, firms still have incentives to lower the quality of their respective product if the market-segmentation effect is large enough to outweigh the cost-increasing effect and the demand-shift effect. Therefore, the qualitative results of our model would remain unchanged.

\subsection{A higher quality increases the marginal cost of production}

We have assumed that the production of a good with higher quality incurs a higher fixed cost, $K(q)$, but does not increase the marginal cost of production. Here, we discuss the case where marginal cost depends on the level of quality.

Suppose that the marginal cost of production depends on $q$ and given by $c(q)$, where $c^{\prime}(q)>0$ and 
$c^{\prime \prime}(q) \geq 0$. The marginal (expected) cost of supplying the authorized good is now given by $c(q)+(1-q) m$. In this case, an increase in $q$ raises the marginal cost of production on the one hand and it decreases the expected cost of repairs on the other hand, as is discussed in Section 4.2.1. An increase in $q$ increases $\Pi^{N}$ and $\Pi^{I}$ if $c^{\prime}(q)<m$ holds, and it decreases them if $c^{\prime}(q)>m$ holds.

Since $c^{\prime \prime}(q) \geq 0$, if $c^{\prime}(1)<m$ holds, an increase in $q$ always reduces the cost of supplying the authorized good. Therefore, it has the same qualitative effects on $\Pi^{N}, \Pi^{I}$, and $\Pi^{R}$ as those in the baseline model. If $c^{\prime}(0)>m$ holds, however, an increase in $q$ always raises the cost of supplying the good. Since the market-segmentation effect from a decrease in $q$ benefits the firm in Regime $R$, it is optimal for the firm to set $q=0$ in all regimes. However, this case is unrealistic that the firm produces the good which always fails.

Finally, if both $c^{\prime}(0)<m$ and $c^{\prime}(1)>m$ hold, there exists a cutoff level of $q, \hat{q}=c^{\prime}(\hat{q})=m$, under which an increase in $q$ decreases the marginal cost of supplying the authorized good and above which it increases the marginal cost. In this case, even if there is no fixed cost of producing the good with a higher quality, $F(q)=0$, the profit of the firm in each regime becomes an inverted-U shaped in $q$ and there is a case where $\tilde{q}^{R}<\tilde{q}^{N}=\tilde{q}^{I}$ will hold.

In sum, as long as the firm chooses a positive level of $q$, the qualitative results remain unchanged even if we consider the positive relationship between the quality and the marginal cost of production.

\section{Conclusion}

In this study, we have re-examined the effect of parallel imports when the firm (trademark holder) of a good might discriminate after-sales services against parallel imported goods. We have shown that the firm is willing to discriminate the repair and maintenance services against the parallel imported good. A refusal to repair parallel imported goods realizes full market segmentation between countries if the quality of the good is sufficiently low. In the middle range of quality, the firm successfully blocks parallel importation even if the price of the authorized good is higher than the price of the parallel imported good. If the quality is sufficiently high, the firm accommodates the parallel imported good and consumers in the importing country buy either the authorized good or the parallel imported good, depending on their willingness to pay for the good. In the latter two cases, the two markets are only partially integrated. Compared with the case where parallel imports are allowed and the firm does not discriminate services, service discrimination hurts consumers in the destination country, while it benefits the firm and consumers in the source country. Despite the service discrimination, allowing parallel imports benefits consumers in the destination country and hurts consumers in the source country, as 
long as the quality of the good is unchanged.

The favorable effect of parallel imports for consumers in the destination country may be overturned, if the firm undertakes costly investments to improve the quality of the product. Without service discrimination, parallel imports have no effect on the quality of the good, because both the price effect and the quantity effect of improving quality are unaffected, and the price gap between countries is independent of the quality. With service discrimination, parallel imports decrease the firm's incentive to improve the quality of the good. This is because the quality of the product is itself a strategic tool to manipulate the degree of vertical differentiation between the authorized good and the parallel imported good. Therefore, with service discrimination, lower quality has an effect to increase the equilibrium price gap between the countries. Consequently, permitting parallel imports reduces the quality of the good in the presence of service discrimination. When the changes in the quality is taken into account, parallel imports may increase the equilibrium price in the destination country because the increased repair cost with lower quality is passed through to the prices of the good, and it may outweigh the conventional price-convergence effect of permitting parallel imports. In this situation, permitting parallel imports may worsen consumers surplus and the social welfare in all countries.

Furthermore, we found that the possible negative effect of parallel importation can be amplified as trade liberalization proceeds. As the import tariff becomes lower, the firm gains more from exports but at the same time it faces increased arbitrage pressure. Then, the firm becomes more willing to reduce the quality for the sake of decreasing the substitutability between the authorized good and the parallel imported good. There is a case where allowing parallel imports benefits consumers and the improves the welfare in the destination country when the import tariff is high, but hurts consumers and worsens the welfare in that country under free trade. If the firm cannot engage in service discrimination, trade liberalization increases the quality, and permitting parallel imports improve consumer surplus, the welfare of the importing country and world welfare.

These results imply that, in contrast to the conventional wisdom, permitting parallel imports may hurt consumers and welfare in all countries if the firm can discriminate services and also manipulate the quality of the good. Countries should implement some restrictions on the firm's service discrimination in allowing parallel imports. Our results also suggest that prohibiting service discrimination becomes more important as trade liberalization proceeds. If it is technically difficult to rule out service discrimination and welfare-worsening parallel imports emerge, the destination country should not allow parallel imports in the first place.

We have conducted some robustness checks. Instead of refusing the repair services, the firm can 
also mitigate the pressure of price arbitrage by charging a relatively high repair price for the parallel imported good. Even if we consider price discrimination in repair services, rather than a simple refusal of repairs, we have confirmed that the qualitative results of this paper remain unchanged. Besides that, if we consider the entry of many competitive independent service organizations, it helps to narrow the international price gap but it is not sufficient to eliminate the firm's service discrimination. Therefore, the main results still go through even in the presence of independent service organizations.

\section{Appendix}

\section{Proof of Lemma 1}

By (11) and (12), we have $\widetilde{p}_{F}^{I}-\widetilde{p}_{F}^{N}=k\left\{\widetilde{p}_{D}^{N}-\left(\widetilde{p}_{F}^{N}+t\right)\right\} /(1+k)>0$ and $\widetilde{p}_{D}^{I}-\widetilde{p}_{D}^{N}=-\left\{\widetilde{p}_{D}^{N}-\left(\widetilde{p}_{F}^{N}+\right.\right.$ $t)\} /(1+k)<0$. Because $\widetilde{p}_{D}^{I}=\widetilde{p}_{F}^{I}+t$ holds, $\widetilde{p}_{D}^{I}>\widetilde{p}_{F}^{I}$. Therefore, we have $\widetilde{p}_{F}^{N}<\widetilde{p}_{F}^{I}<\widetilde{p}_{D}^{I}<\widetilde{p}_{D}^{N}$.

\section{Proof of Lemma 2}

Suppose that the prices of two countries satisfy $p_{D}>\left(p_{F}+t\right) / q$ so that $v_{D}^{A}>v_{D}^{P I}$ holds. Then, the equilibrium prices become $\widetilde{p}_{F}^{R}=\widehat{p}_{F}$ and $\widetilde{p}_{D}^{R}=\widehat{p}_{D}$ (see (26) and (27)). These prices are consistent with the supposition that $p_{D}>\left(p_{F}+t\right) / q$ holds if

$$
\widehat{p}_{D}-\frac{\left(\widehat{p}_{F}+t\right)}{q}=(1-q) \frac{\Gamma(q)}{2 q(q+k)}>0
$$

is satisfied, where $\Gamma(q)=(b+2 m) q^{2}-\{k b+c+2 t+(1-k) m\} q-k(c+t) . \Gamma(q)$ is either U-shaped or decreasing in $q \in[0,1]$. We have $\Gamma(0)=-k(c+t)<0$ and $\Gamma(1)=(1-k) b-(1+k)(c-m)-(2+k) t$. If $b>\{(1+k)(c-m)+(2+k) t\} /(1-k)$ holds, then $\Gamma(1)>0$ and $\Gamma(q)$ is U-shaped in $q$. Therefore, there exists a unique value of $q, q_{H}(\in(0,1))$, that satisfies $\Gamma\left(q_{H}\right)=0$. This means that $\widetilde{p}_{D}^{R}>\left(\widetilde{p}_{F}^{R}+t\right) / q$ holds for $q \in\left(q_{H}, 1\right)$. If $b \leq\{(1+k)(c-m)+(2+k) t\} /(1-k)$ holds, the equilibrium prices satisfy $\widetilde{p}_{D}^{R} \leq\left(\widetilde{p}_{F}^{R}+t\right) / q$, which contradicts the supposition that $p_{D}>\left(p_{F}+t\right) / q$ holds.

Even if a decrease in $q$ reduces the price of the good sold in the domestic country $\left(\widehat{p}_{F}\right)$, it increases the quality-adjusted price of the PI good $\left(\left(\widehat{p}_{F}+t\right) / q\right)$ in the foreign country. The quality adjusted price approaches the infinity as $q$ approaches zero. If a small decrease in $q$ from $q=1$ realizes $\widehat{p}_{D}>\left(\widehat{p}_{F}+t\right) / q$ (i.e., if $\Gamma(1)>0$ holds), $x_{D}^{P I}\left(\widehat{p}_{D}, \widehat{p}_{F}\right)$ is first increased and then decreased as $q$ becomes smaller. This implies that if $q$ is sufficiently small (i.e., $q \leq q_{H}$ ), consumers do not purchase the PI good. If a small decrease in $q$ from $q=1$ results in $\widehat{p}_{D} \leq\left(\widehat{p}_{F}+t\right) / q$ (i.e., if $\Gamma(1) \leq 0$ holds), no consumers purchase the 
PI good irrespective of the level of $q$ if the repair services are not available. For expositional convenience, we set $q_{H}=1$ in this case.

If $q \leq q_{H}$ is satisfied, $v_{D}^{P I} \geq v_{D}^{A}$ holds and all consumers in country $D$ prefer the authorized good, if they buy one. In this case, if $\widetilde{p}_{D}^{N} \leq\left(\widetilde{p}_{F}^{N}+t\right) / q$ holds, the firm is able to block PIs, even if it completely discriminates the prices between the two countries. Therefore, the firm charges $\widetilde{p}_{F}^{R}=\widetilde{p}_{N}^{N}$ and $\widetilde{p}_{D}^{R}=\widetilde{p}_{D}^{N}$ in equilibrium because these are the prices under market segmentation and realize the highest profit for the monopolist. We have $\widetilde{p}_{D}^{N}-\left(\widetilde{p}_{F}^{N}+t\right) / q=\Omega(q) /(2 q)$ where $\Omega(q)=(1-q)\{(1-2 k) q b-c-2 t\}+$ $q\{(1-k) q b-t\}-(1-q)^{2}(k b+m)$. Since $\Omega(q)$ is a quadratic function in $q, \Omega(0)=-(k b+c+2 t+m)<0$, and $\Omega(1)=\{(1-k) b-t\}>0$, there exists a unique value of $q, q_{L}(\in(0,1))$, that satisfies $\Omega\left(q_{L}\right)=0$. This means that $\widetilde{p}_{D}^{N} \geq\left(\widetilde{p}_{F}^{N}+t\right) / q$ holds for $q \in\left[q_{L}, 1\right)$ and $\widetilde{p}_{D}^{N}<\left(\widetilde{p}_{F}^{N}+t\right) / q$ holds for $q \in\left(0, q_{L}\right]$.

By comparing $\widetilde{p}_{D}^{N}-\left(\widetilde{p}_{F}^{N}+t\right) / q$ and $\widehat{p}_{D}-\left(\widehat{p}_{F}+t\right) / q$ defined in $(\mathrm{A} 1)$,

$$
\left(\widetilde{p}_{D}^{N}-\frac{\widetilde{p}_{F}^{N}+t}{q}\right)-\left(\widehat{p}_{D}-\frac{\left(\widehat{p}_{F}+t\right)}{q}\right)=\frac{\left(q^{2}+k\right)\{(b+m) q-(k b+t+m)\}}{2 q(q+k)} .
$$

This equation tells us that $\left[\widetilde{p}_{D}^{N}-\left(\widetilde{p}_{F}+t\right) / q\right]-\left[\widehat{p}_{D}-\left(\widehat{p}_{F}+t\right) / q\right]$ is positive if $q>q_{1} \equiv(k b+t+m) /(b+$ $m)$ is satisfied. At $q=q_{1}$, we have

$$
\begin{aligned}
\left.\left(\widetilde{p}_{D}^{N}-\frac{\widetilde{p}_{F}^{N}+t}{q}\right)\right|_{q=q_{1}} & =\left.\left(\widehat{p}_{D}-\frac{\left(\widehat{p}_{F}+t\right)}{q}\right)\right|_{q=q_{1}} \\
& =-\frac{\{(1-k) b-t\} q_{1}}{2(k b+t+m)^{2}}[b(c-k m)+m(c-m)+b t]<0 .
\end{aligned}
$$

This means that $q_{L}>q_{1}, \widetilde{p}_{D}^{N}-\left(\widetilde{p}_{F}^{N}+t\right) / q=0$, and $\widehat{p}_{D}-\left(\widehat{p}_{F}+t\right) / q<0$ are satisfied at $q=q_{L}$, and $q_{L}$ is lower than $q_{H}$ at which $\widehat{p}_{D}-\left(\widehat{p}_{F}+t\right) / q=0$ holds. Therefore, there exists a unique value of $q, q_{L}$ $\left(\in\left(0, q_{H}\right)\right)$, such that $\widetilde{p}_{D}^{N} \leq\left(\widetilde{p}_{F}^{N}+t\right) / q$ holds for $q \in\left(0, q_{L}\right]$.

We have proved that there exist the threshold values that satisfy $0<q_{L}<q_{H} \leq 1$.

(i) If $q \in\left(q_{H}, 1\right)$ holds, we have $\widetilde{p}_{i}^{R}=\widehat{p}_{i}$ and $\left(\widetilde{p}_{F}^{R}+t\right) / q<\widetilde{p}_{D}^{R}$ is satisfied by the definition of $q_{H}$. In this range of $q$, we have $\widetilde{p}_{D}^{N}-\widetilde{p}_{D}^{R}=k\left(q-q_{1}\right) / 2[(b+m)(q+k)]$ where $q_{1}$ is defined in the proof of Lemma 2. Since $q>q_{1}$ holds whenever $q>q_{L}$ holds, we have $\widetilde{p}_{D}^{N}>\widetilde{p}_{D}^{R}$. Therefore, $\left(\widetilde{p}_{F}^{R}+t\right) / q<\widetilde{p}_{D}^{R}<\widetilde{p}_{D}^{N}$ holds.

(ii) If $q \in\left(q_{L}, q_{H}\right)$ holds, we have $\widetilde{p}_{i}^{R}=\widehat{p}_{i}^{\prime}$. Section 2.3.2 suggests that $\widetilde{p}_{D}^{R}=\left(\widetilde{p}_{F}^{R}+t\right) / q$ holds in this case. Besides that, we have $\widetilde{p}_{D}^{N}-\widetilde{p}_{D}^{R}=q\left\{q \widetilde{p}_{D}^{N}-\left(\widetilde{p}_{F}^{N}+t\right)\right\} /\left(q^{2}+k\right)>0$. Therefore, $\left(\widetilde{p}_{F}^{R}+t\right) / q=\widetilde{p}_{D}^{R}<\widetilde{p}_{D}^{N}$ holds.

(iii) If $q \in\left(0, q_{L}\right]$ holds, we have $\widetilde{p}_{i}^{R}=\widetilde{p}_{i}^{N}$. By the definition of $q_{L}, \widetilde{p}_{D}^{R}=\widetilde{p}_{D}^{N} \leq\left(\widetilde{p}_{F}^{N}+t\right) / q$ holds. 


\section{Proof of Proposition 1}

For convenience, let us prove (i), (ii), and (iii) in the reverse order.

(iii) If $q \in\left(0, q_{L}\right]$ holds, we have $\widetilde{p}_{F}^{R}=\widetilde{p}_{F}^{N}$ by Section 2.3.2. By combining this with Lemmas 1 and 2, we have $\widetilde{p}_{D}^{I}<\widetilde{p}_{D}^{R}=\widetilde{p}_{D}^{N} \leq\left(\widetilde{p}_{F}^{R}+t\right) / q$ and $\widetilde{p}_{F}^{N}=\widetilde{p}_{F}^{R}<\widetilde{p}_{F}^{I}$.

(ii) If $q \in\left(q_{L}, q_{H}\right)$ holds, we have $\widetilde{p}_{i}^{R}=\grave{p}_{i}$. Then, $\widetilde{p}_{D}^{R}-\widetilde{p}_{D}^{I}=(1-q)\left[\left(k+q^{2}\right)\left(p_{F}+t\right)+k(1+q)\left\{q \widetilde{p}_{D}^{N-}\right.\right.$ $\left.\left.\left(\widetilde{p}_{F}^{N}+t\right)\right\}\right] /\left\{q\left(k+q^{2}\right)(k+1)\right\}>0$ holds for because $q \widetilde{p}_{D}^{N}-\left(\widetilde{p}_{F}^{N}+t\right)>0$ holds for $q \in\left(q_{L}, 1\right)$, and $\widetilde{p}_{F}^{R}-\widetilde{p}_{F}^{I}=-k(1-q)\{t+(1+k) m+2 k b\} /\{2(k+1)(q+k)\}<0$ holds. By combining these with Lemmas 1 and 2, we have $\widetilde{p}_{D}^{I}<\left(\widetilde{p}_{F}^{R}+t\right) / q=\widetilde{p}_{D}^{R}<\widetilde{p}_{D}^{N}$ and $\widetilde{p}_{F}^{N}<\widetilde{p}_{F}^{R}<\widetilde{p}_{F}^{I}$.

(i) If $q \in\left(q_{H}, 1\right)$ holds, we have $\widetilde{p}_{i}^{R}=\widehat{p}_{i}$ by Section 2.3.1. By comparing $\widetilde{p}_{F}^{N}$ and $\widetilde{p}_{F}^{R}$, we have $\widetilde{p}_{F}^{N}-\widetilde{p}_{F}^{R}=-q\left(q-q_{1}\right) / 2(q+k)$ where $q_{1}$ is defined in the proof of Lemma 2. Since $q>q_{1}$ holds whenever $q>q_{L}$ holds, $\widetilde{p}_{F}^{N}<\widetilde{p}_{F}^{R}$ and $\widetilde{p}_{D}^{N}<\widehat{p}_{D}$ are always satisfied. By comparing $\widehat{p}_{i}$ and $\grave{p}_{i}$, we have $\widehat{p}_{D}-\grave{p}_{D}=\left\{q \widehat{p}_{D}-\left(\widehat{p}_{F}+t\right)\right\} q^{2} /\left(k+q^{2}\right)>0$ and $\widehat{p}_{F}-\grave{p}_{F}=-\left\{q \widehat{p}_{D}-\left(\widehat{p}_{F}+t\right)\right\} k q /\left(k+q^{2}\right)<0$ hold because $q \widehat{p}_{D}-\left(\widehat{p}_{F}+t\right)>0$ holds in this range of $q$. Because the proof of (ii) shows that $\grave{p}_{D}>\widetilde{p}_{D}^{I}$ and $\grave{p}_{F}<\widetilde{p}_{F}^{I}$ hold for any $q \in\left(q_{L}, 1\right)$, we have $\widetilde{p}_{D}^{R}=\widehat{p}_{D}>\widetilde{p}_{D}^{I}$ and $\widetilde{p}_{F}^{R}=\widehat{p}_{F}<\widetilde{p}_{F}^{I}$. Besides that, we have $\left(\widetilde{p}_{F}^{R}+t\right) / q-\widetilde{p}_{D}^{I}=$ $(1-q)\left[2 b k q+(k+1)\{(k+q)(c-m q)+m q\}+\left(k+2 q+k q+k^{2}\right) t\right] /\{2(k+1)(k+q) q\}>0 . \quad$ By combining these with Lemmas 1 and 2 , we have $\widetilde{p}_{D}^{I}<\left(\widetilde{p}_{F}^{R}+t\right) / q<\widetilde{p}_{D}^{R}<\widetilde{p}_{D}^{N}$ and $\widetilde{p}_{F}^{N}<\widetilde{p}_{F}^{R}<\widetilde{p}_{F}^{I}$.

\section{Proof of Proposition 2}

Irrespective of the level of $q$, we have $\Pi^{I}-\Pi^{N}=-n\left(\Delta p^{N}-t\right)^{2} /\{b(1+k)\}<0$. By (7), (8), (13) and (14), the functional forms of consumer surplus in each country are identical between Regime $N$ and Regime $I$. By Proposition 1, we have $\widetilde{p}_{D}^{I}<\widetilde{p}_{D}^{N}$ and $\widetilde{p}_{F}^{N}<\widetilde{p}_{F}^{I}$ given $q$. Therefore, $C S_{F}^{I}-C S_{F}^{N}=$ $-n\left(\widetilde{p}_{F}^{I}-\widetilde{p}_{F}^{N}\right)\left\{2 k b-\left(\widetilde{p}_{F}^{I}+\widetilde{p}_{F}^{N}\right)\right\} /(2 k b)<0$ and $C S_{D}^{I}-C S_{D}^{N}=n\left(\widetilde{p}_{D}^{N}-\widetilde{p}_{D}^{I}\right)\left\{2 b-\left(\widetilde{p}_{D}^{I}+\widetilde{p}_{D}^{N}\right)\right\} /(2 b)>0$ always hold. Besides that, we have $x_{D}\left(\widetilde{p}_{D}^{N}\right)=n\left(1-\widetilde{p}_{D}^{N} / b\right)<x_{D}\left(\widetilde{p}_{D}^{I}\right)=n\left(1-\widetilde{p}_{D}^{I} / b\right)$. Therefore, $W_{D}^{N}=C S_{D}^{N}+t x_{D}\left(\widetilde{p}_{D}^{N}\right)<W_{D}^{I}=C S_{D}^{I}+t x_{D}\left(\widetilde{p}_{D}^{I}\right)$ and $W_{F}^{I}=C S_{F}^{I}+\Pi^{I}<W_{F}^{N}=C S_{F}^{N}+\Pi^{N}$ hold.

(i) Suppose $q \in\left(q_{L}, 1\right)$ holds. When the firm provides the repair services for the PI good, the firm's profit function becomes the same as that without PIs and it is given by (4). For $q \in\left(q_{L}, q_{H}\right]$, the firm's profit function is also given by (4). In this range of $q$, the firm sets $p_{F}=\grave{p}_{F}$ and $p_{D}=\grave{p}_{D}$ and blocks PIs. without PIs, the firm sets the price that maximizes the profit it can earn in each market. This means that the profit earned in each country is higher as the price becomes closer to the optimal price without PIs. By Proposition 1, $\widetilde{p}_{F}^{I}>\grave{p}_{F}>\widetilde{p}_{F}^{N}$ and $\widetilde{p}_{D}^{N}>\grave{p}_{D}>\widetilde{p}_{D}^{I}$ holds. This means that $\Pi^{N}>\Pi\left(\grave{p}_{D}, \grave{p}_{F}\right)>\Pi^{I}$ holds for $q \in\left(q_{L}, q_{H}\right]$. If $q_{H} \neq 1$, some consumers purchase the PI good that is not subject to repair services in equilibrium, and the equilibrium profit, $\Pi^{+}\left(\widehat{p}_{D}, \widehat{p}_{F}\right)$, satisfies $\Pi^{+}\left(\widehat{p}_{D}, \widehat{p}_{F}\right)>\Pi\left(\grave{p}_{D}, \grave{p}_{F}\right)$ holds 
for $q \in\left(q_{H}, 1\right)$ because the firm chooses $\widehat{p}_{F}$ and $\widehat{p}_{D}$ that satisfies $q \widehat{p}_{D}>\widehat{p}_{F}+t$ and accommodates the imports of the PI good even if it can choose $\grave{p}_{D}$ and $\grave{p}_{F}$ that satisfies $q \grave{p}_{D}=\grave{p}_{F}+t$ to block the imports of the PI good.

Let $\Pi^{N+}$ be the profit of the producer, if it discriminates services and sells the authorized good that is not subject to any repair services, even without PIs. We can prove that $\Pi^{N}>\Pi^{N+}$ holds, that is, the firm has no incentive to discriminate services between the authorized goods in the absence of PIs. Suppose that PIs are banned in country $D$, and the firm has an option to sell two types of the authorized good within the same country - the authorized good that is subject to free repair services, which we call the $S$ good, and the authorized good that is not subject to any repair services, which we call the $N S$ good. Let $p_{i}^{S}$ denote the price of the $S$ good and $p_{i}^{N S}$ denote the price of the $N S$ good. We again set $t=0$ because the tariff does not affect the analysis in this section.

As is Section 2.3, the consumers with $v \geq\left(p_{i}^{S}-p_{i}^{N S}\right) /(1-q)$ purchases the $S$ good, while those with $\left(p_{i}^{S}-p_{i}^{N S}\right) /(1-q)>v>p_{i}^{N S} / q$ purchase the $N S$ good. The demand for the $N S$ good is positive if and only if $q p_{i}^{S}>p_{i}^{N S}$ holds. The profit of the firm in country $i$ is given by

$$
\pi_{i}\left(p_{i}^{S}, p_{i}^{N S}\right)=n\left[p_{i}^{S}-\{c+(1-q) m\}\right]\left[1-\frac{p_{i}^{S}-p_{i}^{N S}}{(1-q) b}\right]+n\left(p_{i}^{N S}-c\right)\left[\frac{q p_{i}^{S}-p_{i}^{N S}}{(1-q) q b}\right] .
$$

By differentiating (A2) with respect to $p_{i}^{N S}$, we have

$$
\frac{\partial \pi_{i}\left(p_{i}^{S}, p_{i}^{N S}\right)}{\partial p_{i}^{N S}}=\frac{n\left\{2\left(q p_{i}^{S}-p_{i}^{N S}\right)+(1-q)(c-q m)\right\}}{(1-q) q b} .
$$

Therefore, as long as the demand for the $N S$ good is positive (i.e., $q p_{i}^{S}>p_{i}^{N S}$ ), an increase in the price of the $N S$ good increases the firm's profit. This means that the firm optimally chooses $p_{i}^{S}$ and $p_{i}^{N S}$ such that $p_{i}^{S}=p_{i}^{N S} / q$ holds and eliminates the market for the authorized good for which repair services are not provided. Therefore, $\Pi^{N}>\Pi^{N+}$ holds. In regime $R$, the firm faces PIs and it must take into account the price in country $F$ in setting the optimal price in country $D$. Because of this constraint, $\Pi^{N+} \geq \Pi^{+}\left(\widehat{p}_{F}, \widehat{p}_{D}\right)$ holds. Therefore, $\Pi^{I}<\Pi^{R}<\Pi^{N}$ holds for all $q \in\left(q_{L}, 1\right)$.

For $q \in\left(q_{H}, 1\right)$, some consumers in country $D$ purchase the PI good and other consumers purchase the authorized good. In this case, the functional form of consumer surplus of country $D$ in Regime $R$, which is given by (28), is different from those in Regime $N$ and Regime $I$. By Proposition 1 , the move from Regime $N$ to $R$ increases, while the move from Regime $I$ to $R$ decreases, both the price of the authorized good and the quality adjusted price of the PI good (i.e., $\left.\widetilde{p}_{D}^{I}<\left(\widetilde{p}_{F}^{R}+t\right) / q<\widetilde{p}_{D}^{R}<\widetilde{p}_{D}^{N}\right)$. This implies that $C S_{D}^{N}<C S_{D}^{R}<C S_{D}^{I}$ holds in $q \in\left(q_{H}, 1\right)$. Since the functional form of consumer surplus of country $F$ in Regime $R$ is still the same as the those in the other two regimes, $\widetilde{p}_{F}^{N}<\widetilde{p}_{F}^{R}<\widetilde{p}_{F}^{I}$ means that $C S_{F}^{I}<C S_{F}^{R}<C S_{F}^{N}$ holds given $q \in\left(q_{H}, 1\right)$. For $q \in\left(q_{L}, q_{H}\right]$, all consumers purchase the 
authorized good in Regime $R$ and the functional forms of consumer surplus in each country become identical across the three regimes. Since $\widetilde{p}_{F}^{N}<\widetilde{p}_{F}^{R}<\widetilde{p}_{F}^{I}$ and $\widetilde{p}_{D}^{I}<\widetilde{p}_{D}^{R}<\widetilde{p}_{D}^{N}$ hold by Proposition 1 . Hence, $C S_{F}^{I}<C S_{F}^{R}<C S_{F}^{N}$ and $C S_{D}^{N}<C S_{D}^{R}<C S_{D}^{I}$ hold.

Because $C S_{F}^{I}<C S_{F}^{R}<C S_{F}^{N}$ and $\Pi^{I}<\Pi^{R}<\Pi^{N}$ holds, $W_{F}^{I}=C S_{F}^{I}+\Pi^{I}<W_{F}^{R}=C S_{F}^{R}+\Pi^{R}<$ $W_{F}^{N}=C S_{F}^{N}+\Pi^{N}$ holds. By (2) and (23), the total imports of country $D$ in the three regimes satisfy $x_{D}\left(\widetilde{p}_{D}^{N}\right)=n\left(1-\widetilde{p}_{D}^{N} / b\right)<x_{D}^{A}\left(\widetilde{p}_{D}^{R}, \widetilde{p}_{F}^{R}\right)+x_{D}^{P I}\left(\widetilde{p}_{D}^{R}, \widetilde{p}_{F}^{R}\right)=n\left\{1-\left(\widetilde{p}_{F}^{R}+t\right) /(q b)\right\}<x_{D}\left(\widetilde{p}_{D}^{I}\right)=n\left(1-\widetilde{p}_{D}^{I} / b\right)$, because $\widetilde{p}_{D}^{I}<\left(\widetilde{p}_{F}^{R}+t\right) / q<\widetilde{p}_{D}^{R}$ holds by Proposition 1. Therefore, we have $W_{F}^{I}=C S_{F}^{I}+\Pi^{I}<$ $W_{F}^{R}=C S_{F}^{R}+\Pi^{R}<W_{F}^{N}=C S_{F}^{N}+\Pi^{N}$ and $W_{D}^{N}=C S_{D}^{N}+t x_{D}\left(\widetilde{p}_{D}^{N}\right)<W_{D}^{R}=C S_{D}^{R}+t\left\{x_{D}^{A}\left(\widetilde{p}_{D}^{R}, \widetilde{p}_{F}^{R}\right)+\right.$ $\left.x_{D}^{P I}\left(\widetilde{p}_{D}^{R}, \widetilde{p}_{F}^{R}\right)\right\}<W_{D}^{I}=C S_{D}^{I}+t x_{D}\left(\widetilde{p}_{D}^{I}\right)$.

(ii) Suppose $q \in\left(0, q_{L}\right]$ holds. In this range of $q$, PIs with service discrimination have no effect on the equilibrium prices, $\widetilde{p}_{i}^{R}=\widetilde{p}_{i}^{N}(i=D, F)$. Therefore, $\Pi^{I}<\Pi^{R}=\Pi^{N}, C S_{F}^{I}<C S_{F}^{R}=C S_{F}^{N}$, $C S_{D}^{N}=C S_{D}^{R}<C S_{D}^{I}, W_{D}^{N}=W_{D}^{R}<W_{D}^{I}$, and $W_{F}^{I}<W_{F}^{R}=W_{F}^{N}$ hold given $q$.

\section{Proof of Proposition 3}

(i) Suppose $q \in\left(q_{L}, 1\right)$ holds. Let $W W^{+}\left(\widehat{p}_{D}, \widehat{p}_{F}\right)$ denote the world welfare in Regime $R$ when the firm sets the prices such that it accommodates PIs (i.e., $\left.q \in\left(q_{H}, 1\right)\right)$ and $W W\left(\grave{p}_{D}, \grave{p}_{F}\right)$ denote the world welfare in the same regime when the firm sets the prices such that it blocks PIs (i.e., $q \in\left(q_{L}, q_{H}\right]$ ). We have $W W^{\prime}\left(\widehat{p}_{D}, \widehat{p}_{F}\right)-W W\left(\grave{p}_{D}, \grave{p}_{F}\right)=-(1-q) n \Gamma(q)[\Gamma(q)+4\{(k+q)(c-m q)+m q(1-q)+$ $q t\}] /\left\{8 b q(k+q)\left(k+q^{2}\right)\right\}<0$ because $\Gamma(q)>0$ holds if the firm chooses to accommodate PIs (see the proof of Proposition 1). This means that, if $W W\left(\grave{p}_{D}, \grave{p}_{F}\right)<W W^{I}$ holds, $W W^{R}<W W^{I}$ for all $q \in\left(q_{L}, 1\right)$. We have $W W^{I}-W W\left(\grave{p}_{D}, \grave{p}_{F}\right)=(1-q) n[\{b-(c+(1-q) m)\}\{3(q-k)+1-$ $k q\} b k+3(1-q)(1+k)\left\{c^{2}+(1-q)^{2} m^{2}\right\}+2(1-q)(1+k)\{3(1-q) c+(4-q) t\} m+(1+q)(4+k) t^{2}+$ $2\{(4-q)(1+k) c+(1-k+2 q) k b\} t] /\left\{8 q(k+1)\left(k+q^{2}\right)\right\}>0$. Hence, $W W^{R}<W W^{I}$ holds. Besides that, for $q \in\left(q_{H}, 1\right), W W^{+}\left(\widehat{p}_{D}, \widehat{p}_{F}\right)-W W^{N}=n \Psi_{1} /\{8 q(k+q) b\}$ where $\Psi_{1} \equiv q\{(k-q) b\}^{2}-2 q(k-$ $q)((1-q) m+t\} b+3(1-q)(q+k) c^{2}+2(1-q)(k+q)(t-3 m q) c-3 q(1-q)\left(1-q-k q-q^{2}\right) m^{2}-$ $2 q(1-q)(3+k+q) m t-\{(1-q) k+(4-q) q\} t^{2}$. Since $\Gamma(q)>0$ holds in $q \in\left(q_{H}, 1\right)$ and $\Gamma(q)>0$ requires $b(q-k)>\{(k+q) c+q(1-k-2 q) m+(k+2 q) t\} / q, \Psi_{1}>\left.\Psi_{1}\right|_{b(q-k)=\{(k+q) c+q(1-k-2 q) m+(k+2 q) t\} / q}=$ $(k+q)(c+t-m q)\left\{\left(k+4 q-3 q^{2}\right) c+q\left(4-k-8 q+3 q^{2}\right) m+\left(k+4 q+q^{2}\right) t\right\} / q>(k+q)(c+t-$ $m q)\left\{m(1-q)\left(k+8 q-3 q^{2}\right)+\left(k+4 q+q^{2}\right) t\right\} / q>0$. Hence, $W W^{+}\left(\widehat{p}_{D}, \widehat{p}_{F}\right)>W W^{N}$ holds for $q \in\left(q_{H}, 1\right)$. For $q \in\left(q_{L}, q_{H}\right], W W\left(\grave{p}_{D}, \grave{p}_{F}\right)-W W^{N}=n \Omega(q)\left[\Omega(q)+4\left\{(1-q) c+(1-q)^{2} m+\right.\right.$ $t\}] /\left\{8\left(k+q^{2}\right) b\right\}>0$ holds since $\Omega(q)>0$ holds for $q \in\left(q_{L}, 1\right)$ (see the proof of Proposition 1$)$. Hence, $W W^{+}\left(\widehat{p}_{D}, \widehat{p}_{F}\right)>W W^{N}$ holds for $q \in\left(q_{L}, q_{H}\right]$. Therefore, $W W^{N}<W W^{R}<W W^{I}$ always holds for 
$q \in\left(q_{L}, 1\right)$.

(ii) For $q \in\left(0, q_{L}\right]$, the equilibrium outcomes in Regime $R$ coincide with those in Regime $N$. For any $q \in(0,1), W W^{I}-W W^{N}=N\{(1-b) k+3 t\}\{(1-b) k-t\} / 8 b(k+1)>0$ holds by Assumption 1 . Therefore, we have $W W^{N}=W W^{R}<W W^{I}$.

\section{Proof of Proposition 5}

Under the numerical example in Figure 4, $\widetilde{q}^{N}=\widetilde{q}^{I}=0.69737>\widetilde{q}^{R}=0.51538$ holds. Given $\widetilde{q}^{N}$ and $\widetilde{q}^{R}$, we have $\left.C S_{D}^{R}\right|_{q=\widetilde{q}^{R}}-\left.C S_{D}^{N}\right|_{q=\widetilde{q}^{N}}=-0.70619,\left.\left\{W_{D}^{R}-K(q)\right\}\right|_{q=\widetilde{q}^{R}}-\left.\left\{W_{D}^{N}-K(q)\right\}\right|_{q=\widetilde{q}^{N}}=-5.6970$, and $\left.W W^{R}\right|_{q=\widetilde{q}^{R}}-\left.W W^{N}\right|_{q=\widetilde{q}^{N}}=-6.5369$. Therefore, there is a case where $C S_{D}^{R}<C S_{D}^{N}, W_{D}^{R}<W_{D}^{N}$, and $W W^{R}<W W^{N}$ hold when $q$ is endogenously determined.

\section{Proof of Proposition 6}

Let us set $\beta=120$ and keep the other parameters the same as those in Figure 4 . Then, trade liberalization from $t_{0}=4.57$ to $t_{1}=0$ increases the optimal level of quality without PIs as well as that under PIs without service discrimination from $\left.\widetilde{q}^{N}\right|_{t=t_{0}}=\left.\widetilde{q}^{I}\right|_{t=t_{0}}=0.55903$ to $\left.\widetilde{q}^{N}\right|_{t=t_{1}}=\left.\widetilde{q}^{I}\right|_{t=t_{1}}=0.60870$, where $\left.q_{L}\right|_{t=t_{0}}=0.55816,\left.q_{L}\right|_{t=t_{1}}=0.55816,\left.q_{H}\right|_{t=t_{0}}=0.76879$ and $\left.q_{H}\right|_{t=t_{1}}=0.76879$. However, it decreases the optimal level of quality under service discrimination from $\left.\widetilde{q}^{R}\right|_{t=t_{0}}=0.55819$ to $\left.\widetilde{q}^{R}\right|_{t=t_{1}}=0.41919$.

With the numerical calculations above, changes in consumer surplus, welfare of country $D$, and world welfare with $t=t_{0}$ become $\left.C S_{D}^{R}\right|_{q=\widetilde{q}^{R}}-\left.C S_{D}^{N}\right|_{q=\widetilde{q}^{N}}=0.70340,\left.W_{D}^{R}\right|_{q=\widetilde{q}^{R}}-\left.W_{D}^{N}\right|_{q=\widetilde{q}^{N}}=0.91764$, and $\left.W W^{R}\right|_{q=\widetilde{q}^{R}}-\left.W W^{N}\right|_{q=\widetilde{q}^{N}}=0.58536$. These changes with $t=t_{1}$ become $\left.C S_{D}^{R}\right|_{q=\widetilde{q}^{R}}-\left.C S_{D}^{N}\right|_{q=\widetilde{q}^{N}}=$ $\left.W_{D}^{R}\right|_{q=\widetilde{q}^{R}}-\left.W_{D}^{N}\right|_{q=\widetilde{q}^{N}}=-0.66338$ and $\left.W W^{R}\right|_{q=\widetilde{q}^{R}}-\left.W W^{N}\right|_{q=\widetilde{q}^{N}}=-7.3833$. Hence, when $q$ is endogenously determined, there is a case where $C S_{D}^{N}<C S_{D}^{R}, W_{D}^{N}<W_{D}^{R}$, and $W W^{N}<W W^{R}$ hold at $t=t_{0}$, but $C S_{D}^{R}<C S_{D}^{N}, W_{D}^{R}<W_{D}^{N}$, and $W W^{R}<W W^{N}$ hold at $t=t_{1}<t_{0}$.

\section{Proof of Proposition 7}

If a consumer in country $D$ buys a PI good and pays for repair services, his/her expected utility becomes

$$
U_{D}^{P I, r}=v-\left(p_{F}+t\right)-(1-q) r
$$

By comparing (15) and (A2), consumers prefer to buy the authorized good, rather than purchasing the PI good and paying for the repair services, if the overall price of the PI good is less than the price of the authorized good, $p_{D}>p_{F}+t+(1-q) r$. Because the expected quality of the authorized good and the quality of the PI good become identical, the consumers purchase the good with the lower overall 
price. If $p_{D}=p_{F}+t+(1-q) r$ holds, consumers are indifferent between the authorized good and the PI good. If $p_{D}<p_{F}+t+(1-q) r$ holds, all consumers prefer the authorized good because the repair price is too high. This case can be regarded as the refusal of repairs.

For the time being, let us suppose $p_{D}>\left(p_{F}+t\right)+(1-q) r$ holds and all consumers in country $D$ purchase the PI good. We assume the firm continues to provide a full warranty for the authorized good. If a consumer buys a PI good but does not utilize the repair services provided by the firm, then her expected utility is given by (16). Therefore, consumers purchase the repair services if their willingness to pay for quality satisfies $v \geq r$. By comparing $r$ and $v_{D}^{P I}$, we have

$$
r-v_{D}^{P I}=\frac{q r-\left(p_{F}+t\right)}{q}
$$

If $r>\left(p_{F}+t\right) / q$ holds, which means that the repair price for the PI good is sufficiently high, consumers with parameter $v \in\left[v_{D}^{P I}, r\right]$ buy the PI good but do not purchase the repair services. Suppose this inequality holds, then the demand for the PI good purchased by the consumers who will purchase the repair services in country $D$ is given by

$$
x_{D}^{P I, r}(r)=n f_{D}[b-r]=n\left[1-\frac{r}{b}\right]
$$

and the demand for the PI good purchased by the consumers who do not purchase the repair services in country $D$ is given by

$$
x_{D}^{P I, n r}\left(p_{F}, r\right)=n f_{D}\left[r-v_{D}^{P I}\right]=n\left[\frac{q r-\left(p_{F}+t\right)}{q b}\right] .
$$

The demand of the good in country $F$ is given by (1). The firm' profit in this situation is given by

$$
\begin{aligned}
\Pi^{*}\left(p_{F}, r\right)= & {\left[p_{F}-\{c+(1-q) m\}\right] x_{F}\left(p_{F}\right)+\left[p_{F}+(1-q) r-\{c+(1-q) m\}\right] x_{D}^{P I, r}(r) } \\
& +\left(p_{F}-c\right) x_{D}^{P I, n r}\left(p_{F}, r\right) .
\end{aligned}
$$

By maximizing $\Pi^{*}\left(p_{F}, r\right)$ with respect to $p_{F}$ and $r$, we have the optimal prices as

$$
\begin{aligned}
p_{F}^{*} & =\frac{(2 q b-t) k+m q(1-q)+c(k+q)}{2(k+q)}, \\
r^{*} & =\frac{(b+m)}{2} .
\end{aligned}
$$

We confirm that $p_{F}^{*}=\widehat{p}_{F}$ holds. By using $(27), \widehat{p}_{D}=\widehat{p}_{F}+t+(1-q)(b+m) / 2=p_{F}^{*}+t+(1-q) r^{*}$ holds. Therefore, the overall price for the PI good in country $D$ coincides with the price of the authorized good under the refusal to repair. The condition of $x_{D}^{I P, n r}\left(p_{F}^{*}, r^{*}\right)>0, r^{*}>\left(p_{F}^{*}+t\right) / q$, can be transformed into $\widehat{p}_{D}>\left(\widehat{p}_{F}+t\right) / q$, the condition under which the firm accommodates the PI good in the case of the 
refusal of repairs. Therefore, some consumers who purchased the PI good leave the PI good unrepaired if $q \in\left(q_{H}, 1\right)$ holds.

If $r^{*} \leq\left(p_{F}^{*}+t\right) / q$ holds, which means that $q \leq q_{H}$ holds, we have $x_{D}^{P I, n r}\left(p_{F}^{*}, r^{*}\right) \leq 0$ with $p_{F}^{*}$ and $r^{*}$. In this case, $x_{D}^{P I, n r}\left(p_{F}, r\right) \geq 0$ becomes binding constraint and the firm cannot set $p_{F}$ and $r$ separately. In this case, the firm sets the prices such that all consumers who purchase the PI good also purchase the repair services (i.e., $\left.x_{D}^{P I, n r}\left(p_{F}, r\right)=0\right)$. The firm maximizes $\Pi^{*}\left(p_{F}, r\right)$ such that $r=\left(p_{F}+t\right) / q$ holds, and we confirm the equilibrium prices, $p_{F}^{* *}$ and $r^{* *}$, satisfy $\grave{p}_{D}=p_{F}^{* *}+t+(1-q) r^{* *}$.

Under full market segmentation, by (9), $\widetilde{p}_{D}^{N}=\widetilde{p}_{F}^{N}+t+\{(1-k) b-t\} / 2$ holds. This implies that if the firm sets the repair price, $\bar{r}$, such that $(1-q) \bar{r}=\{(1-k) b-t\} / 2$ and $\bar{r}<\left(\widetilde{p}_{F}^{N}+t\right) / q$ is satisfied, the firm can practically set the same prices as those under the full price discrimination. The inequality can be transformed into $\widetilde{p}_{D}<\left(\widetilde{p}_{F}+t\right) / q$, the same condition under which the refusal of repairs realizes the full market segmentation. The full market segmentation occurs if $q \in\left(0, q_{L}\right)$ holds.

In sum, the overall price of the good in each country and the cut-off values of $q$ that are obtained with the price discrimination in repair services becomes the same as those obtained with the refusal of repairs.

\section{References}

[1] Ahmadi, R.. and B. R. Young (2000) "Parallel imports: challenges from unauthorized distribution channels," Marketing Science 19(3), pp.279-294.

[2] Anderson, S. P. and V. A. Ginsburgh (1999) "International pricing with costly consumer arbitrage," Review of International Economics 7(1), pp.126-139.

[3] Bulow, J. (1986) "An economic theory of planned obsolescence," Quarterly Journal of Economics 101(4), pp.729-750.

[4] Chen, K.-P., H.-P. Lai, and Y.-T. Yu (2013) "Do consumers discount parallel imports?," AsiaPacific Journal of Accounting and Economics 21(1), pp.58-77.

[5] Choi J. P. (2001) "Planned obsolescence as a signal of quality," International Economic Journal 15(4), pp.59-79.

[6] Fethke, G. and R. Jagannathan (2002) "Monopoly with endogenous durability." Journal of Economic Dynamics and Control 26(6), pp.1009-1027. 
[7] Ganslandt, M. and K.E. Maskus (2004). "Parallel imports and the pricing of pharmaceutical products: Evidence from the European Union." Journal of Health Economics 23(5), pp.1035-1057.

[8] Goering, G. E. (2007) "Durability choice with differentiated products." Research in Economics 61(2), pp.105-112.

[9] Goering, G. E. and M. K. Pippenger (2002) "Strategic trade policy with endogenous product durability." The International Trade Journal 16(2), pp.181-201.

[10] Grigoriadis, L. G. (2014) Trade Marks and Free Trade: A Global Analysis, Cham: Springer, New York.

[11] Grossman. G .M. and E. L-.C. Lai (2008) "Parallel imports and price control," RAND Journal of Economics 39(2), pp.378-402.

[12] Hwang, H., C.-H. Peng, and P.-C. Shih (2014) "Parallel imports, product innovation and market structure," International Review of Economics and Finance 34, pp. 237-45.

[13] Ishikawa, J. (2004) "From segmented markets to integrated markets: an analysis of economic integration and antidumping legislation," Review of International Economics 12(4), pp.706-722.

[14] Ishikawa, J., H. Morita, and H. Mukunoki (2016) "Trade liberalization and aftermarket services for imports," Economic Theory 62(4), pp.719-764.

[15] Knox, D. and M. Richardson (2002) "Trade policy and parallel imports," European Journal of Political Economy 19(1), pp.133-151

[16] Li, C. and Maskus, K. E. (2006) "The impact of parallel imports on investment in cost-reducing research and development," Journal of International Economics 68(2), pp.443-455.

[17] Malueg, D. A. and M. Schwartz (1994) "Parallel imports, demand dispersion, and international price discrimination," Journal of International Economics 37(3-4), pp.167-195.

[18] Maskus, K. E. (2000) "Parallel imports," The World Economy 23(9), pp.1269-1284.

[19] Maskus, K. E. and Y. Chen (2004) "Vertical price control and parallel imports: Theory and evidence," Review of International Economics 12(4), pp.551-570.

[20] Matsushima, N. and T. Matsumura (2010) "Profit-enhancing parallel imports," Open Economies Review 21, pp.433-447. 
[21] Matteucci, G. and P. Reverberi (2014) "Parallel trade, product quality, and welfare," Economics Letters 122, pp.258-262.

[22] Mueller-Langer, F. (2012) "Parallel trade and its ambiguous effects on global welfare," Review of International Economics 20(1), pp.177-185.

[23] Mukherjee, A. and L. Zhao (2012) "Profitable parallel trade in unionized markets," Journal of Economics 107(3), pp. 267-76.

[24] NERA (1999) The Economic Consequences of the Choice of a Regime of Exhaustion in the Area of Trademarks, Final Report for DGXV of the Commission, London, February.

[25] Raff, H. and N. Schmitt (2007) "Why parallel trade may raise producers' profits," Journal of International Economics 71(2), pp.434-447.

[26] Richardson, M. (2002) "An elementary proposition concerning parallel imports," Journal of International Economics 56(1), pp.233-245.

[27] Roy, S. and K. Saggi (2012a) "Equilibrium parallel import policies and international market structure," Journal of International Economics 87(2), pp.262-276.

[28] Roy, S. and K. Saggi (2012b) "Strategic competition and optimal parallel import policy," Canadian Journal of Economics 45(4), pp.1369-1396.

[29] Schwartz, M. (1990) "Third-degree price discrimination and output: Generalizing a welfare result," American Economic Review 80(5), pp.1259-1262.

[30] Strausz, R. (2009) "Planned obsolescence as an incentive device for unobservable quality," Economic Journal 119(540), pp.1405-1421.

[31] Valleti, T. M. (2006) "Differential pricing, parallel trade, and the incentive to invest," Journal of International Economics 70(1), pp.314-324.

[32] Waldman, M. (1996a) "Planned obsolescence and the R\&D decision," RAND Journal of Economics 27(3), pp.583-595.

[33] Waldman, M. (1996b) "Durable goods pricing when quality matters," Journal of Business 69(4), pp.489-510. 
[34] Yeung, G. and V. Mok (2013) "Manufacturing and distribution strategies, distribution channels, and transaction costs: The case of parallel imported automobiles," Managerial and Decision Economics $34(1)$, pp. $44-58$. 
Figure 1: No PIs $(N)$ and PIs without service discrimination (I)

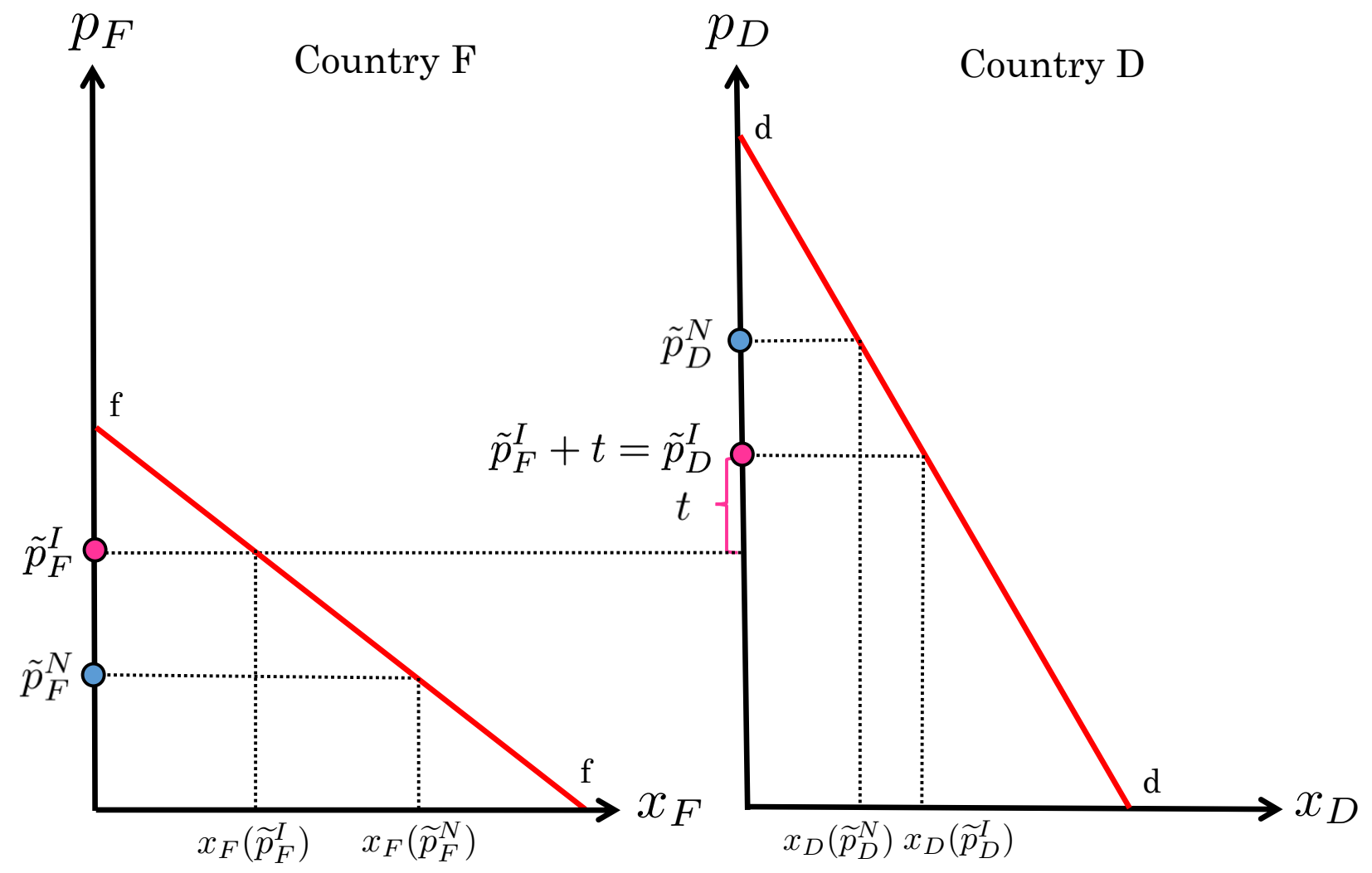


Figure 2: PIs with service discrimination $(R)$ and high quality

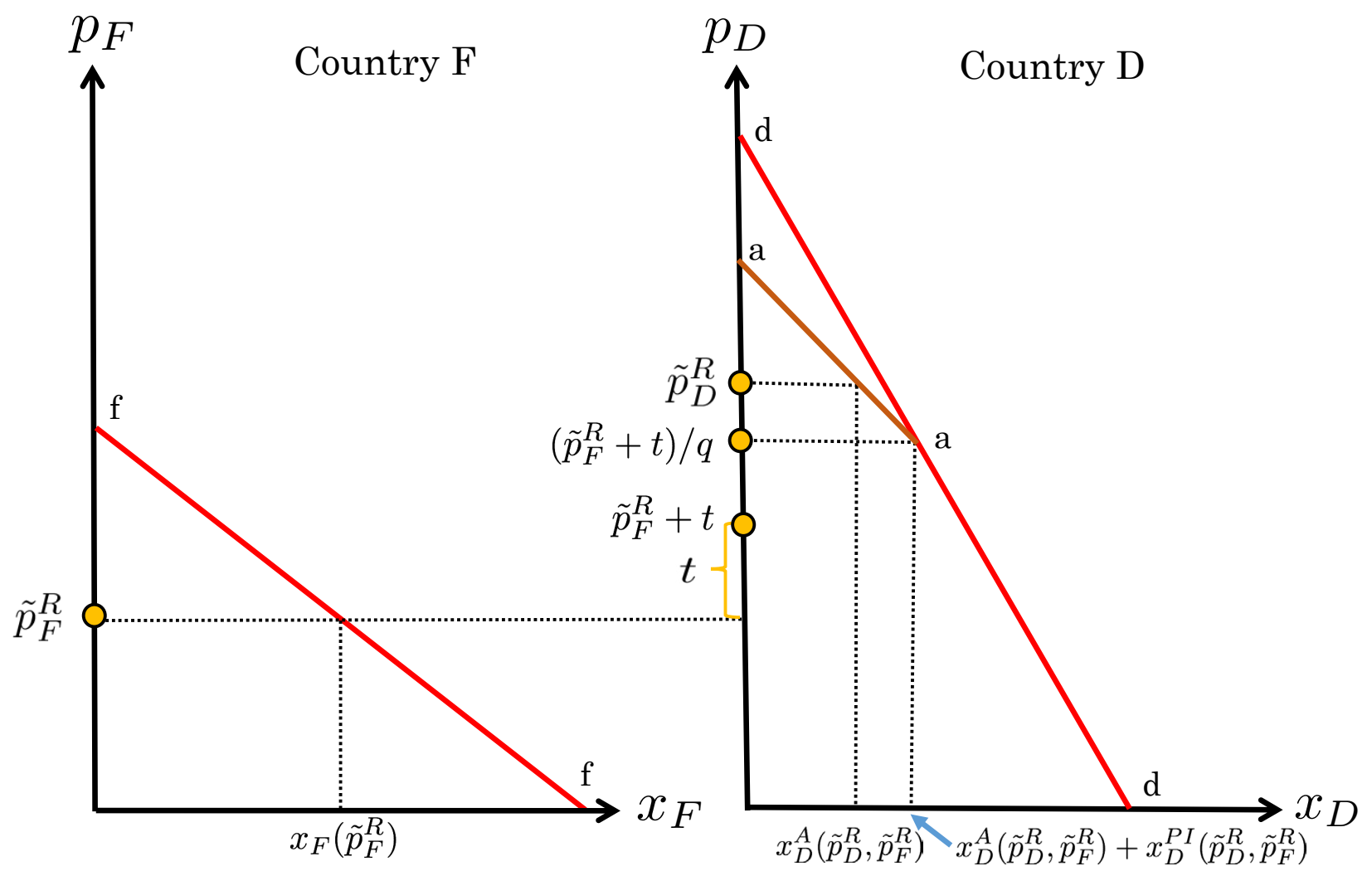


Figure 3: PIs with service discrimination $(R)$ and middle quality

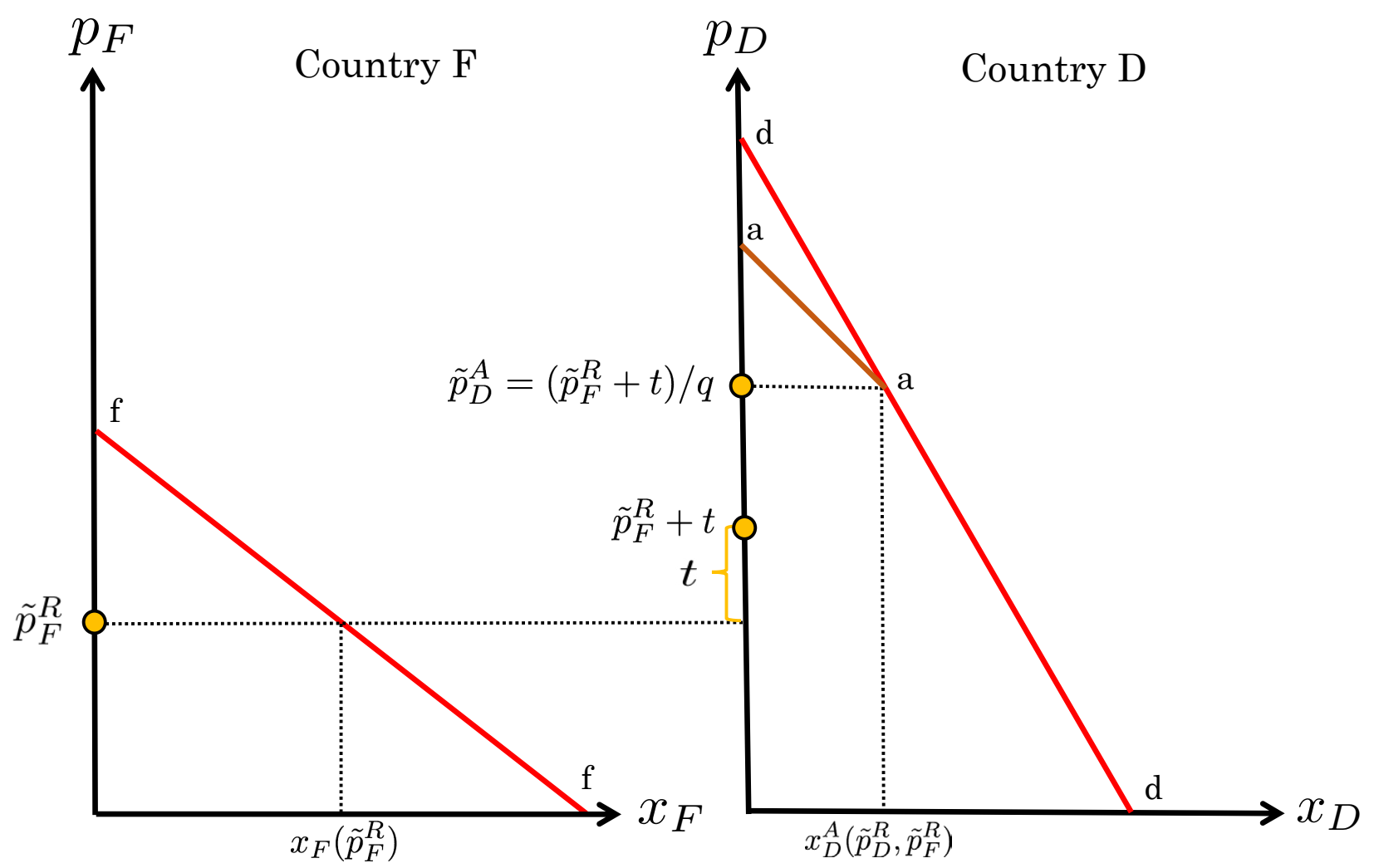


Figure 4: Endogenous quality

Monopolist's profit - fixed cost

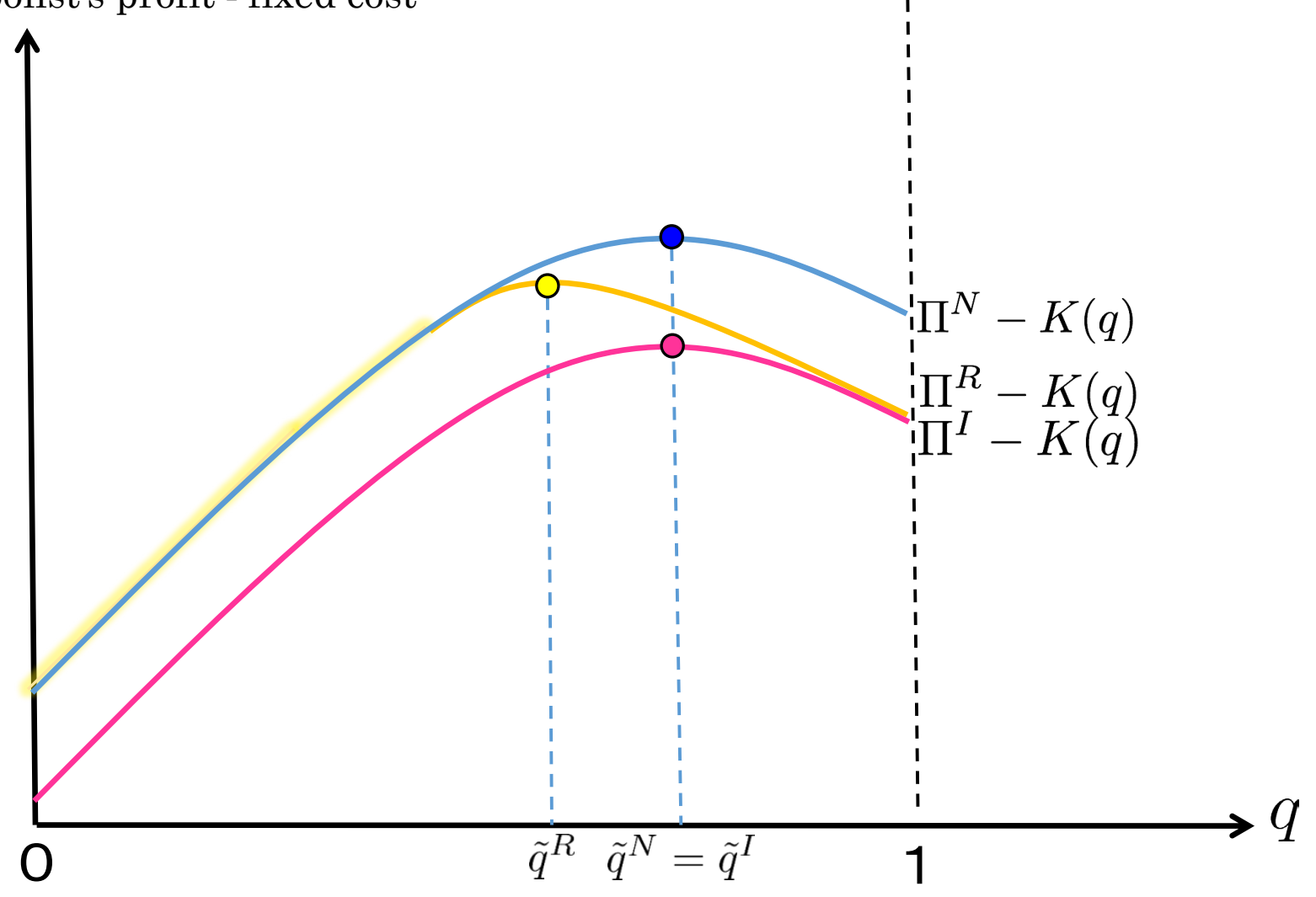


Figure 5: Trade liberalization and the optimal quality

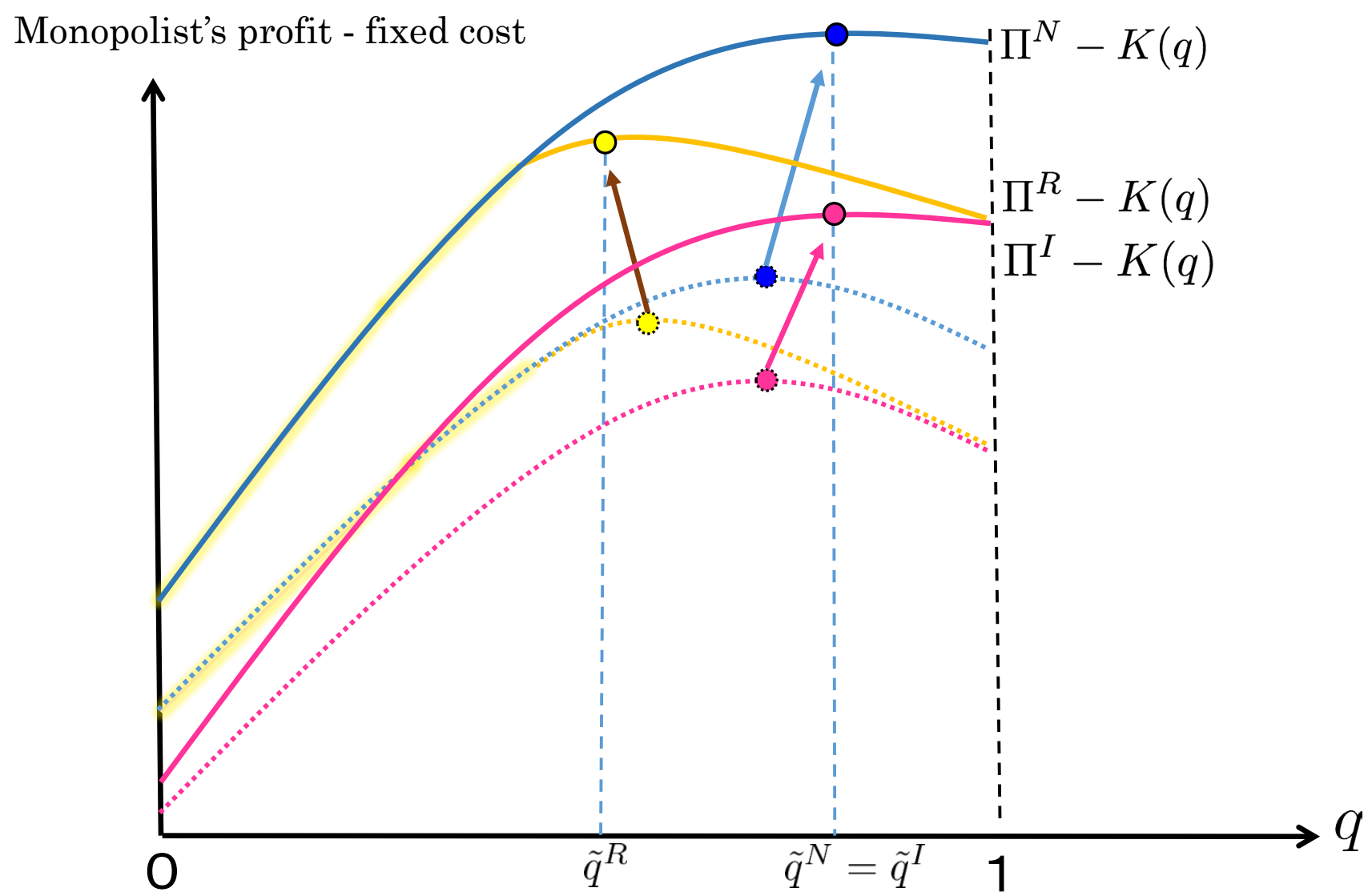

